\title{
Inflow Motions Associated with High-mass Protostellar Objects
}

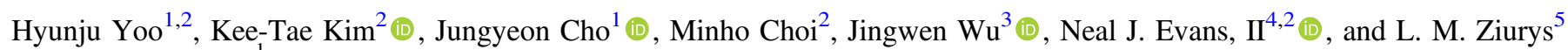 \\ ${ }^{1}$ Department of Astronomy and Space Science, Chungnam National University, Daejeon, Republic of Korea \\ ${ }^{2}$ Korea Astronomy and Space Science Institute, 776 Daedeokdae-ro, Yuseong-gu, Daejeon 34055, Republic of Korea \\ ${ }^{3}$ National Astronomical Observatories, Chinese Academy of Sciences, 20A Datun Road, Chaoyang District, Beijing, 100012, People's Republic of China \\ ${ }^{4}$ Department of Astronomy, The University of Texas at Austin, 2515 Speedway, Stop C1400, Austin, TX 78712-1205, USA \\ ${ }^{5}$ Department of Chemistry, Department of Astronomy, Arizona Radio Observatory, and Steward Observatory, \\ University of Arizona, 933 N. Cherry Avenue, Tucson, AZ 85721, USA \\ Received 2017 July 4; revised 2018 February 20; accepted 2018 February 26; published 2018 April 2
}

\begin{abstract}
We performed a molecular line survey of 82 high-mass protostellar objects in a search for inflow signatures associated with high-mass star formation. Using the $\mathrm{H}^{13} \mathrm{CO}^{+}(1-0)$ line as an optically thin tracer, we detected a statistically significant excess of blue asymmetric line profiles in the $\mathrm{HCO}^{+}(1-0)$ transition, but nonsignificant excesses in the $\mathrm{HCO}^{+}(3-2)$ and $\mathrm{H}_{2} \mathrm{CO}\left(2_{12}-1_{11}\right)$ transitions. The negative blue excess for the $\mathrm{HCN}(3-2)$ transition suggests that the line profiles are affected by dynamics other than inflow motion. The $\mathrm{HCO}^{+}(1-0)$ transition thus seems to be the suitable tracer of inflow motions in high-mass star-forming regions, as previously suggested. We found 27 inflow candidates that have at least 1 blue asymmetric profile and no red asymmetric profile, and derived the inflow velocities to be $0.23-2.00 \mathrm{~km} \mathrm{~s}^{-1}$ for 20 of them using a simple two-layer radiative transfer model. Our sample is divided into two groups in different evolutionary stages. The blue excess of the group in relatively earlier evolutionary stages was estimated to be slightly higher than that of the other in the $\mathrm{HCO}^{+}(1-0)$ transition.
\end{abstract}

Key words: ISM: kinematics and dynamics - ISM: molecules - radio lines: ISM - stars: formation

\section{Introduction}

High-mass stars (mass $>8 M_{\odot}$, luminosity $>10^{3} L_{\odot}$ ) have great physical and chemical importance in interstellar environments. They affect the energetics of galaxies via jets/outflows, strong radiation, and supernova explosions, and play a role in triggering next-generation star formation with the associated shocks. Furthermore, they enrich the surrounding systems and change chemical abundances. In spite of the importance of highmass stars, there still remain questions about their formation process, due to difficulties arising from observational and evolutionary limitations. In order to investigate the formation of high-mass stars, it is necessary to identify sources in different evolutionary phases, especially the protostellar stage, and to understand their environments.

Gravitational collapse is the most important and fundamental key process in the early stages of star formation. Unfortunately, collapsing motion is relatively harder to observe than other motions (e.g., rotation, outflow). According to the "inside-out" collapse model and observations of low-mass protostellar cores (Shu 1977; Zhou et al. 1993; Myers et al. 1996; Evans 1999, 2003), an asymmetric double-peaked velocity profile with a higher peak at the blueshifted part (hereafter, blue profile) can be a tool for detecting inflow signatures. The blue profile depends on the optical depth of the observed line and the velocity of the inflowing material. Therefore, finding adequate inflow tracers for target sources is necessary to enhance our understanding. In this work, we study inflow motions toward high-mass star-forming regions using several molecular transitions and try to identify suitable inflow tracers.

Although inflow motion is difficult to observe, several surveys detected statistically significant evidence of inflow motions via observations of blue profiles toward low-mass star-forming regions. The molecular line surveys with various transitions indicate that active inflow motions exist regardless of the evolutionary stages of low-mass star formation (Gregersen et al.
1997, 2000; Mardones et al. 1997; Evans 2003). Therefore, gravitational collapse is a generally accepted phenomenon for low-mass star formation both theoretically and observationally.

On the other hand, inflow studies of high-mass star-forming regions toward different samples in different inflow-tracing molecular lines show inconsistent fractions of blue asymmetries (Wu \& Evans 2003; Fuller et al. 2005; Purcell et al. 2006; Wyrowski et al. 2006; Wu et al. 2007; Reiter et al. 2011; He et al. 2015; Jin et al. 2016, see Section 3.1 for detailed results). Such studies are expected to give us clues for understanding the influence and importance of gravitational collapse on the formation and evolution of high-mass stars. Furthermore, they may enable us to discuss similarities between high-mass starforming process and its low-mass counterpart. However, it is difficult not only to characterize the evolutionary stages of highmass star-forming regions, but also to find appropriate inflow tracers. Accordingly, to understand the formation of high-mass stars there should be more comprehensive research of adequate targets, using advanced facilities.

In this study, we surveyed 82 high-mass protostellar object (HMPO) candidates in multiple molecular lines using singledish telescopes to investigate the inflow motions via statistical analysis of the observed line spectra. We present the source selection criteria in Section 2.1 and the observational details in Section 2.2. Statistical analyses with line profiles are in Section 3.1 and identifications of inflow candidates and examinations of their characteristics are in Section 3.2. We discuss the appropriateness of determining profiles and statistics depending on sub-groups in Section 4. Finally, we conclude with a summary of the main results in Section 5.

\section{Source Selection and Observations}

\subsection{Source Selection}

In order to find potential sites of early stages of star formation, Richards et al. (1987) proposed selection criteria for 
identifying bright compact molecular clouds from the IRAS (InfraRed Astronomical Satellite) point source catalog. Meanwhile, Wood \& Churchwell (1989) suggested IRAS color criteria for ultra-compact $\mathrm{H}$ II regions (UCH IIs), [25-12] 0.57 and $[60-12] \geqq 1.30{ }^{6}$ Palla et al. (1991) combined those two sets of criteria to discover bright infrared sources in the very early phases of high-mass star formation without positional coincidence with known $\mathrm{H}$ II regions or extragalactic objects. They found 260 IRAS point sources and distinguished them into two groups. In the IRAS color-color diagram of [25-12] and [60-12], 125 of the 260 sources are in the region meeting the criteria of Wood \& Churchwell (1989), while the remaining 135 are outside the region. They classified the 125 sources as the High group and the 135 sources as the Low group. Molinari et al. (1996) observed 163 of the 260 sources in the $\mathrm{NH}_{3}(1,1)$ and $(2,2)$ lines, which are believed to be tracers of warm dense gas in the vicinity of embedded (proto) stars, in a search for HMPO candidates. They detected $\mathrm{NH}_{3}$ line emission in 101 sources. The detection rate of $\mathrm{NH}_{3}$ emission is considerably higher for the High group (80\% of 80 sources) than for the Low group (45\% of 83 sources). Together with the finding of Palla et al. (1991) that the detection rate of $\mathrm{H}_{2} \mathrm{O}$ maser emission is significantly higher in the High group (26\%) than in the Low group (9\%), this might suggest that the two groups represent different evolutionary phases of high-mass star formation, i.e., the Low group is in an earlier evolutionary stage than the High group (Molinari et al. 1998). We selected 72 of the $101 \mathrm{NH}_{3}$-detected sources in the catalog of Molinari et al. (1996): 47 High and 25 Low sources. We also added 10 High sources from the HMPO candidate catalogs of Walsh et al. (1998, 2001), Hunter et al. (2000), and Sridharan et al. (2002). Table 1 presents information for these 82 sources, such as the IRAS names, equatorial coordinates, kinematic distances $\left(d_{\text {kin }}\right)$, and infrared luminosities $\left(L_{\mathrm{IR}}\right)$. We adopted the information from the original catalogs, except for the distances and luminosities for IRAS 05391-0152 (Qin et al. 2008), IRAS 06084-0611 (Gómez et al. 2002), and IRAS 07427-2400 (Kumar et al. 2002).

\subsection{Observations}

We made single-point observations toward the 82 sources in up to 5 transitions, such as the $\mathrm{HCO}^{+}(1-0), \mathrm{HCO}^{+}(3-2)$, $\mathrm{HCN}(3-2), \mathrm{H}_{2} \mathrm{CO}\left(2_{12}-1_{11}\right)$ and $\mathrm{H}^{13} \mathrm{CO}^{+}(1-0)$ lines. The used telescopes were the Caltech Submillimeter Observatory (CSO) $10.4 \mathrm{~m}$, the Arizona Radio Observatory (ARO) $12 \mathrm{~m}$, the Submillimeter Telescope (SMT) $10 \mathrm{~m}$, and the Korean VLBI Network (KVN) $21 \mathrm{~m}$. Table 2 summarizes the observational details, including the observed transition, frequency, telescope, main-beam size of the telescope, main-beam efficiency of the telescope, velocity resolution, and number of observed sources.

\subsubsection{CSO $10.4 \mathrm{~m}$ Observations}

We used the CSO telescope to survey 48 sources in the $\mathrm{HCN}(3-2)$ line and 11 sources in the $\mathrm{HCO}^{+}(3-2)$ line. The observations were undertaken in 2005 October. The system temperatures ranged between 350 and $500 \mathrm{~K}$. We employed the $50 \mathrm{MHz}$ bandwidth acousto-optical spectrometer (AOS) with 1024 channels as the backend and obtained typical

\footnotetext{
6 Here, $\left[\lambda_{2}-\lambda_{1}\right]$ is defined as $\log _{10}\left[F_{\lambda 2} / F_{\lambda 1}\right]$, where $F_{\lambda i}$ is the flux density in wavelength band $\lambda_{i}$ in units of $\mu \mathrm{m}$.
}

Table 1

Source Information

\begin{tabular}{|c|c|c|c|c|c|}
\hline $\begin{array}{l}\text { IRAS } \\
\text { Name }\end{array}$ & $\begin{array}{l}\text { R.A. } \\
\text { (J2000) }\end{array}$ & $\begin{array}{c}\text { Decl. } \\
(\mathbf{J} 2000)\end{array}$ & $\begin{array}{c}d_{\mathrm{kin}} \\
(\mathrm{kpc})\end{array}$ & $\begin{array}{l}L_{\mathrm{IR}} \\
\left(L_{\odot}\right)\end{array}$ & Grot \\
\hline $00117+6412$ & 001427.7 & +642846 & 1.80 & $1.38 \mathrm{E}+03$ & $\mathrm{H}$ \\
\hline $00420+5530$ & 004457.6 & +554718 & 7.72 & $5.15 \mathrm{E}+04$ & $\mathrm{~L}$ \\
\hline $04579+4703$ & 050139.7 & +470723 & 2.47 & $3.91 \mathrm{E}+03$ & $\mathrm{H}$ \\
\hline $05137+3919$ & $0517 \quad 13.3$ & +392223 & 10.8 & $5.61 \mathrm{E}+04$ & $\mathrm{~L}$ \\
\hline $05168+3634$ & 052016.2 & +363721 & 6.08 & $2.40 \mathrm{E}+04$ & $\mathrm{H}$ \\
\hline $05274+3345$ & 053045.6 & +334752 & 1.55 & $4.53 \mathrm{E}+03$ & $\mathrm{H}$ \\
\hline $05345+3157$ & 053747.8 & +315924 & 1.80 & $1.38 \mathrm{E}+03$ & $\mathrm{~L}$ \\
\hline $05358+3543^{\mathrm{b}}$ & 053910.4 & +354519 & 1.80 & $6.31 \mathrm{E}+03$ & $\mathrm{H}$ \\
\hline $05373+2349$ & 054024.4 & +235054 & 1.17 & $6.64 \mathrm{E}+02$ & $\mathrm{~L}$ \\
\hline $05391-0152^{\mathrm{c}}$ & 054138.7 & -015119 & 0.50 & $1.96 \mathrm{E}+03$ & $\mathrm{H}$ \\
\hline $05393-0156^{\mathrm{c}}$ & 054149.5 & -015517 & 0.50 & $1.10 \mathrm{E}+04$ & $\mathrm{H}$ \\
\hline $05490+2658^{b}$ & 055213.0 & +265934 & 2.10 & $3.16 \mathrm{E}+03$ & $\mathrm{H}$ \\
\hline $05553+1631$ & 055813.9 & +163200 & 3.04 & $1.17 \mathrm{E}+04$ & $\mathrm{H}$ \\
\hline $06053-0622^{\mathrm{c}}$ & 060746.7 & -062300 & 0.80 & $2.90 \mathrm{E}+04$ & $\mathrm{H}$ \\
\hline $06056+2131$ & 060841.0 & +213101 & 1.50 & $5.83 \mathrm{E}+03$ & $\mathrm{H}$ \\
\hline $06061+2151$ & 060907.8 & +215039 & 0.10 & $2.78 \mathrm{E}+01$ & $\mathrm{H}$ \\
\hline $06084-0611^{\mathrm{c}}$ & 061051.0 & -061154 & 1.00 & $9.60 \mathrm{E}+03$ & $\mathrm{H}$ \\
\hline $06103+1523$ & 061315.1 & +152236 & 4.63 & $1.91 \mathrm{E}+04$ & $\mathrm{H}$ \\
\hline $06105+1756$ & 061328.3 & +175533 & 3.38 & $1.60 \mathrm{E}+04$ & $\mathrm{H}$ \\
\hline $06382+0939$ & 064102.7 & +093610 & 0.76 & $1.63 \mathrm{E}+02$ & $\mathrm{~L}$ \\
\hline $06584-0852$ & 070051.5 & -085629 & 4.48 & $9.08 \mathrm{E}+03$ & $\mathrm{~L}$ \\
\hline $07299-1651^{\mathrm{c}}$ & 073210.0 & -165815 & 1.40 & $6.30 \mathrm{E}+03$ & $\mathrm{H}$ \\
\hline $07427-2400^{\mathrm{c}}$ & 074451.9 & -240741 & 6.40 & $5.00 \mathrm{E}+04$ & $\mathrm{H}$ \\
\hline $17417-2851$ & 174453.4 & -285220 & 0.10 & $3.17 \mathrm{E}+01$ & $\mathrm{H}$ \\
\hline $17450-2742$ & 174809.3 & -274321 & 0.10 & $1.57 \mathrm{E}+01$ & $\mathrm{~L}$ \\
\hline $17504-2519$ & 175335.2 & -251956 & 3.65 & $9.32 \mathrm{E}+03$ & $\mathrm{H}$ \\
\hline $17527-2439$ & 175549.1 & -244020 & 3.23 & $1.53 \mathrm{E}+04$ & $\mathrm{H}$ \\
\hline $18014-2428$ & 180429.3 & -242847 & 2.87 & $1.71 \mathrm{E}+04$ & $\mathrm{~L}$ \\
\hline $18018-2426$ & 180453.9 & -242641 & 1.50 & $6.64 \mathrm{E}+03$ & $\mathrm{~L}$ \\
\hline $18024-2119$ & 180525.4 & -211941 & 0.12 & $1.08 \mathrm{E}+01$ & $\mathrm{~L}$ \\
\hline $18089-1732$ & 181151.3 & -173128 & 3.48 & $6.33 \mathrm{E}+04$ & $\mathrm{H}$ \\
\hline $18134-1942$ & 181622.3 & -194120 & 1.62 & $7.62 \mathrm{E}+03$ & $\mathrm{H}$ \\
\hline $18144-1723$ & 181724.4 & $-1722 \quad 13$ & 4.33 & $1.32 \mathrm{E}+04$ & $\mathrm{~L}$ \\
\hline $18151-1208$ & 181757.1 & -120722 & 3.04 & $3.32 \mathrm{E}+04$ & $\mathrm{H}$ \\
\hline $18159-1550$ & 181847.6 & -154854 & 4.66 & $3.10 \mathrm{E}+04$ & $\mathrm{H}$ \\
\hline $18159-1648$ & 181853.5 & -164739 & 2.50 & $2.95 \mathrm{E}+04$ & $\mathrm{H}$ \\
\hline $18162-1612$ & 181907.5 & -161121 & 4.89 & $2.94 \mathrm{E}+04$ & $\mathrm{~L}$ \\
\hline $18236-1205$ & 182624.3 & -120347 & 2.51 & $1.04 \mathrm{E}+04$ & $\mathrm{H}$ \\
\hline $18256-0742$ & 182820.5 & -074022 & 2.90 & $1.11 \mathrm{E}+04$ & $\mathrm{~L}$ \\
\hline $18258-0737$ & 182834.1 & -073531 & 2.97 & $3.31 \mathrm{E}+04$ & $\mathrm{H}$ \\
\hline $18316-0602$ & 183419.8 & -055944 & 3.17 & $4.14 \mathrm{E}+04$ & $\mathrm{H}$ \\
\hline $18317-0513$ & 183425.9 & -051059 & 3.13 & $3.48 \mathrm{E}+04$ & $\mathrm{H}$ \\
\hline $18360-0537$ & 183840.3 & -053506 & 6.28 & $1.16 \mathrm{E}+05$ & $\mathrm{H}$ \\
\hline $18372-0541$ & 183956.0 & -053849 & 1.87 & $7.18 \mathrm{E}+03$ & $\mathrm{H}$ \\
\hline $18396-0431$ & 184218.8 & -042837 & 6.08 & $4.23 \mathrm{E}+04$ & $\mathrm{~L}$ \\
\hline $18488+0000$ & 185124.8 & +000419 & 5.48 & $5.14 \mathrm{E}+04$ & $\mathrm{H}$ \\
\hline $18507+0121$ & 185317.4 & +012455 & 3.87 & $4.84 \mathrm{E}+04$ & $\mathrm{H}$ \\
\hline $18511+0146$ & 185338.1 & +015027 & 3.86 & $2.01 \mathrm{E}+04$ & $\mathrm{~L}$ \\
\hline $18527+0301$ & 185516.5 & +030507 & 5.26 & $1.63 \mathrm{E}+04$ & $\mathrm{~L}$ \\
\hline $18532+0047$ & 185550.6 & +005122 & 3.96 & $1.27 \mathrm{E}+04$ & $\mathrm{H}$ \\
\hline $18565+0349$ & 185903.4 & +035322 & 6.77 & $2.62 \mathrm{E}+04$ & $\mathrm{~L}$ \\
\hline $18566+0408$ & 185909.9 & +041214 & 6.76 & $1.02 \mathrm{E}+05$ & $\mathrm{H}$ \\
\hline $18567+0700$ & 185913.6 & +070447 & 2.16 & $8.39 \mathrm{E}+03$ & $\mathrm{~L}$ \\
\hline $19045+0518$ & 190659.3 & +052255 & 3.80 & $1.09 \mathrm{E}+04$ & $\mathrm{H}$ \\
\hline $19088+0902$ & 191115.9 & +090727 & 4.71 & $2.99 \mathrm{E}+04$ & $\mathrm{H}$ \\
\hline $19282+1814$ & 193028.1 & +182053 & 2.11 & $1.63 \mathrm{E}+04$ & $\mathrm{H}$ \\
\hline $19368+2239$ & 193858.1 & +224632 & 4.44 & $8.63 \mathrm{E}+03$ & $\mathrm{H}$ \\
\hline $20050+2720$ & 200706.7 & +272853 & 0.73 & $3.88 \mathrm{E}+02$ & $\mathrm{H}$ \\
\hline $20056+3350$ & 200731.5 & +335939 & 1.67 & $4.00 \mathrm{E}+03$ & $\mathrm{H}$ \\
\hline $20062+3550$ & 200809.8 & +355920 & 0.08 & $5.40 \mathrm{E}+00$ & $\mathrm{H}$ \\
\hline $20106+3545$ & 201231.3 & +355446 & 1.64 & $1.79 \mathrm{E}+03$ & $\mathrm{~L}$ \\
\hline $20126+4104$ & 201426.0 & $+41 \quad 1332$ & 4.18 & $7.12 \mathrm{E}+04$ & $\mathrm{H}$ \\
\hline $20188+3928$ & 202039.3 & +393752 & 0.31 & $3.43 \mathrm{E}+02$ & $\mathrm{H}$ \\
\hline $20220+3728$ & 202355.7 & +373810 & 4.49 & $8.09 \mathrm{E}+04$ & $\mathrm{H}$ \\
\hline
\end{tabular}


Table 1

(Continued)

\begin{tabular}{|c|c|c|c|c|c|}
\hline $\begin{array}{l}\text { IRAS } \\
\text { Name }\end{array}$ & $\begin{array}{c}\text { R.A. } \\
(\mathrm{J} 2000)\end{array}$ & $\begin{array}{c}\text { Decl. } \\
(\mathrm{J} 2000)\end{array}$ & $\begin{array}{c}d_{\text {kin }} \\
(\mathrm{kpc})\end{array}$ & $\begin{array}{l}L_{\mathrm{IR}} \\
\left(L_{\odot}\right)\end{array}$ & Group $^{a}$ \\
\hline $20227+4154$ & 202431.4 & +420417 & 0.10 & $9.14 \mathrm{E}+00$ & $\mathrm{H}$ \\
\hline $20278+3521$ & 202946.9 & +353139 & 5.02 & $1.08 \mathrm{E}+04$ & $\mathrm{~L}$ \\
\hline $20286+4105$ & 203027.9 & +411548 & 3.72 & $3.90 \mathrm{E}+04$ & $\mathrm{H}$ \\
\hline $20333+4102$ & 203509.5 & +411318 & 0.10 & $4.57 \mathrm{E}+01$ & $\mathrm{~L}$ \\
\hline $21078+5211$ & 210925.2 & +522344 & 1.49 & $1.34 \mathrm{E}+04$ & $\mathrm{H}$ \\
\hline $21391+5802$ & 214042.4 & +581610 & 0.75 & $9.39 \mathrm{E}+01$ & $\mathrm{H}$ \\
\hline $21519+5613$ & 215339.2 & +562746 & 7.30 & $1.91 \mathrm{E}+04$ & $\mathrm{H}$ \\
\hline $22172+5549$ & 221909.0 & +560445 & 2.87 & $4.78 \mathrm{E}+03$ & $\mathrm{~L}$ \\
\hline $22198+6336$ & 222127.6 & +635142 & 1.28 & $1.24 \mathrm{E}+03$ & $\mathrm{H}$ \\
\hline $22267+6244$ & 222829.3 & +625944 & 0.45 & $1.10 \mathrm{E}+02$ & $\mathrm{H}$ \\
\hline $22272+6358$ & 222852.2 & +641344 & 1.23 & $1.97 \mathrm{E}+03$ & $\mathrm{H}$ \\
\hline $22308+5812^{d}$ & 223246.1 & +582822 & 3.70 & $2.09 \mathrm{E}+04$ & $\mathrm{H}$ \\
\hline $22506+5944$ & 225238.6 & +600056 & 5.70 & $2.22 \mathrm{E}+04$ & $\mathrm{H}$ \\
\hline $23026+5948$ & 230445.7 & +600435 & 5.76 & $1.76 \mathrm{E}+04$ & $\mathrm{~L}$ \\
\hline $23133+6050^{\mathrm{d}}$ & 231531.5 & +610708 & 5.20 & $1.20 \mathrm{E}+05$ & $\mathrm{H}$ \\
\hline $23140+6121$ & 231611.7 & +613745 & 6.44 & $4.35 \mathrm{E}+04$ & $\mathrm{~L}$ \\
\hline $23314+6033$ & 233344.4 & +605030 & 2.78 & $1.09 \mathrm{E}+04$ & $\mathrm{~L}$ \\
\hline $23545+6508$ & 235705.2 & +652511 & 1.27 & $3.89 \mathrm{E}+03$ & $\mathrm{H}$ \\
\hline
\end{tabular}

Notes.

${ }^{\mathrm{a}} \mathrm{H}$ and $\mathrm{L}$ are abbreviations of the High and Low groups, respectively.

b From Sridharan et al. (2002).

${ }^{c}$ From Walsh et al. (1998).

${ }^{\mathrm{d}}$ From Hunter et al. (2000).

rms noise levels $\left(T_{\mathrm{A}}^{*}\right)$ of $0.17 \mathrm{~K}$ and $0.27 \mathrm{~K}$ at a velocity resolution of $0.22 \mathrm{~km} \mathrm{~s}^{-1}$ after smoothing for $\mathrm{HCN}(3-2)$ and $\mathrm{HCO}^{+}(3-2)$, respectively.

\subsubsection{ARO $12 \mathrm{~m}$ and SMT Observations}

We surveyed 60,52 , and 45 sources in the $\mathrm{HCO}^{+}(1-0)$, $\mathrm{H}_{2} \mathrm{CO}\left(2_{12}-1_{11}\right)$, and $\mathrm{H}^{13} \mathrm{CO}^{+}(1-0)$ lines, respectively, using the older-generation $12 \mathrm{~m}$ telescope. The backends were filterbanks with 256 channels and a bandwidth of $25.6 \mathrm{MHz}$ (100 kHz resolution). The system temperatures were around $350 \mathrm{~K}$ at $\sim 89 \mathrm{GHz}$ and $400 \mathrm{~K}$ at $140 \mathrm{GHz}$. The receivers were dual polarization, single-sideband SIS systems where the image rejection was typically $20 \mathrm{~dB}$, obtained by tuning the mixer backshort. The observed temperatures were obtained on the $T_{\mathrm{R}}^{*}$ scale (Mangnum 2000). The rms noise levels were $0.07 \mathrm{~K}$ at $\sim 0.34 \mathrm{~km} \mathrm{~s}^{-1}$ resolution and $0.08 \mathrm{~K}$ at $0.21 \mathrm{~km} \mathrm{~s}^{-1}$ resolution for $\sim 89$ and $140 \mathrm{GHz}$, respectively.

We also surveyed 32 sources in the $\mathrm{HCO}^{+}(3-2)$ line using the SMT. The $64 \mathrm{MHz}$ filterbanks with 256 channels were used with a spectral resolution of $250 \mathrm{kHz}$. The system temperatures were around $900 \mathrm{~K}$. The single polarization receiver in this case utilized the ALMA Band 6 sideband-separating SIS mixers. The observed temperatures were obtained on the $T_{\mathrm{A}}^{*}$ scale. The rms noise level was $0.12 \mathrm{~K}$ at a resolution of $0.28 \mathrm{~km} \mathrm{~s}^{-1}$. These observations were all conducted in 2006 June.

\subsubsection{KVN $21 \mathrm{~m}$ Observations}

We observed 14,19 , and 30 sources in the $\mathrm{HCO}^{+}(1-0)$, $\mathrm{H}_{2} \mathrm{CO}\left(2_{12}-1_{11}\right)$, and $\mathrm{H}^{13} \mathrm{CO}^{+}(1-0)$ lines, respectively, using the KVN $21 \mathrm{~m}$ telescopes at the Yonsei and Tamna stations (Kim et al. 2011). The observations were performed in 2014
May and June, 2015 February, and 2016 June. The system temperatures usually ranged between 200 and $300 \mathrm{~K}$. The backends were the digital spectrometers with 4096 channels and a bandwidth of $64 \mathrm{MHz}$ each. The noise levels $\left(T_{\mathrm{A}}^{*}\right)$ were typically $0.04,0.06$, and $0.02 \mathrm{~K}$ at velocity resolutions of 0.21 , 0.27 , and $0.22 \mathrm{~km} \mathrm{~s}^{-1}$ after smoothing for the $\mathrm{HCO}^{+}(1-0)$, $\mathrm{H}_{2} \mathrm{CO}\left(2_{12}-1_{11}\right)$, and $\mathrm{H}^{13} \mathrm{CO}^{+}(1-0)$ transitions, respectively, with two exceptions. The velocity resolution was $0.43 \mathrm{~km} \mathrm{~s}^{-1}$ for IRAS $05137+3919$ and IRAS $05345+3157$ in the $\mathrm{H}^{13} \mathrm{CO}^{+}(1-0)$.

\section{Results}

\subsection{Line Asymmetries}

Mardones et al. (1997) proposed a dimensionless parameter $\delta v$ to quantify the asymmetry of the observed optically thick line profiles: $\delta v=\left(v_{\text {thick }}-v_{\text {thin }}\right) / \Delta v_{\text {thin }}$. Here, $v_{\text {thin }}$ and $v_{\text {thick }}$ are the peak velocities of the optically thin and thick lines, respectively, and $\Delta v_{\text {thin }}$ is the full width at half maximum (FWHM) of the optically thin line. This parameter has been generally used in previous inflow studies of low- and highmass star-forming regions. The $v_{\text {thick }}$ is directly obtained from the observed profile, while $v_{\text {thin }}$ and $\Delta v_{\text {thin }}$ are measured by Gaussian fitting to the observed profile. The optically thin line used in this study is the $\mathrm{H}^{13} \mathrm{CO}^{+}(1-0)$ line. Table 3 presents the determined parameters for the optically thin and thick lines. In order to confirm that $\mathrm{H}^{13} \mathrm{CO}^{+}(1-0)$ line emission is optically thin, we derived the peak optical depth, $\tau_{\text {thin }}$, using the following equations:

$$
\tau_{\text {thin }}=-\ln \left[1-\frac{T_{\text {thin }}}{\left(T_{\mathrm{ex}}-J_{\nu}\left(T_{\mathrm{bg}}\right)\right)}\right],
$$

and

$$
J_{\nu}(T)=\frac{h \nu}{k} \frac{1}{\left(e^{h \nu / k T}-1\right)} .
$$

Here, $T_{\text {thin }}$ is the brightness temperature of the optically thin line, $\mathrm{H}^{13} \mathrm{CO}^{+}(1-0)$ in this work, and $T_{\mathrm{bg}}$ is the background brightness temperature, which is assumed to be $2.73 \mathrm{~K}$. We assumed that the $\mathrm{HCO}^{+}(1-0)$ line is optically thick $\left(1-e^{-\tau} \approx 1\right)$ and that both $\mathrm{HCO}^{+}(1-0)$ and $\mathrm{H}^{13} \mathrm{CO}^{+}(1-0)$ lines arise from the same volume with the same excitation temperature, $T_{\mathrm{ex}}$. The excitation temperature can be calculated from the equation

$$
T_{\mathrm{ex}}=\frac{h \nu}{k}\left[\ln \left(1+\frac{(h \nu / k)}{T_{\text {thick }}+J_{\nu}\left(T_{\mathrm{bg}}\right)}\right)\right]^{-1},
$$

where $T_{\text {thick }}$ is the brightness temperature of the optically thick line, $\mathrm{HCO}^{+}(1-0)$. Table 3 lists the estimated optical depths of the $\mathrm{H}^{13} \mathrm{CO}^{+}(1-0)$ line emission in the second column. The values range from 0.04 to 0.36 , with an average value of 0.13 . Thus, the $\mathrm{H}^{13} \mathrm{CO}^{+}(1-0)$ line emission seems to be optically thin enough to measure the systemic velocity and the velocity dispersion of the target clumps. The above assumption of the same emitting volume and excitation temperature for the $\mathrm{HCO}^{+}$and $\mathrm{H}^{13} \mathrm{CO}^{+}$lines may be questionable because of different optical depths. That makes the two lines trace 
Table 2

Summary of the Observations

\begin{tabular}{|c|c|c|c|c|c|c|}
\hline $\begin{array}{l}\text { Observed } \\
\text { Transition }\end{array}$ & $\begin{array}{l}\text { Frequency } \\
(\mathrm{GHz})\end{array}$ & Telescope & $\begin{array}{c}\theta_{\mathrm{mb}} \\
\left({ }^{\prime \prime}\right)\end{array}$ & $\eta_{\mathrm{mb}}$ & $\begin{array}{c}\Delta v \\
\left(\mathrm{~km} \mathrm{~s}^{-1}\right)\end{array}$ & $\begin{array}{l}\text { Number } \\
\text { of Sources }\end{array}$ \\
\hline \multirow[t]{2}{*}{$\mathrm{HCO}^{+}(1-0)$} & 89.188526 & ARO $12 \mathrm{~m}$ & 70 & $0.95^{\mathrm{a}}$ & 0.34 & 60 \\
\hline & & KVN $21 \mathrm{~m}$ & 32 & 0.38 & 0.21 & 14 \\
\hline \multirow[t]{2}{*}{$\mathrm{HCO}^{+}(3-2)$} & 267.557633 & CSO $10.4 \mathrm{~m}$ & 27 & 0.61 & 0.22 & 11 \\
\hline & & SMT $10 \mathrm{~m}$ & 28 & 0.78 & 0.28 & 32 \\
\hline $\mathrm{HCN}(3-2)$ & 265.886431 & CSO $10.4 \mathrm{~m}$ & 27 & 0.61 & 0.22 & 48 \\
\hline \multirow[t]{2}{*}{$\mathrm{H}_{2} \mathrm{CO}\left(2_{12}-1_{11}\right)$} & 140.839515 & ARO $12 \mathrm{~m}$ & 44 & $0.80^{\mathrm{a}}$ & 0.21 & 52 \\
\hline & & KVN $21 \mathrm{~m}$ & 24 & 0.27 & 0.27 & 19 \\
\hline \multirow[t]{2}{*}{$\mathrm{H}^{13} \mathrm{CO}^{+}(1-0)$} & 86.754330 & ARO $12 \mathrm{~m}$ & 72 & $0.95^{\mathrm{a}}$ & 0.35 & 45 \\
\hline & & KVN $21 \mathrm{~m}$ & 32 & 0.38 & 0.22 & 30 \\
\hline
\end{tabular}

Note.

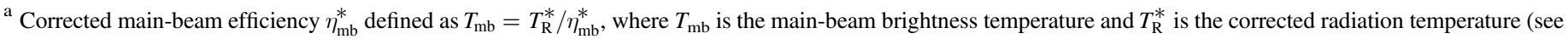
Mangum 2000).

different depths of the clump and hence different volumes. However, the $\mathrm{H}^{13} \mathrm{CO}^{+}$line seems to be practically the best choice because other molecular lines might trace more different volumes.

As in most previous inflow studies (e.g., Gregersen et al. 1997; Mardones et al. 1997; Fuller et al. 2005), we categorized the optically thick line profiles into three types on the basis of the measured value of $\delta v$ : blue (B) for $\delta v<-0.25$, red (R) for $\delta v>0.25$, neither $(\mathrm{N})$ for $-0.25 \leqslant \delta v \leqslant 0.25$. Figure 1 displays sample $\mathrm{HCO}^{+}(1-0)$ spectra with $\mathrm{B}, \mathrm{N}$, and $\mathrm{R}$ profiles, along with the $\mathrm{H}^{13} \mathrm{CO}^{+}(1-0)$ spectra. We counted the numbers of $\mathrm{B}, \mathrm{R}$, and $\mathrm{N}$ profiles $\left(N_{\mathrm{Blue}}, N_{\text {Red }}, N_{\text {Neither }}\right.$, and $\left.N_{\text {Total }} \equiv N_{\text {Blue }}+N_{\text {Red }}+N_{\text {Neither }}\right)$ for each optically thick line. The detection rates of blue profiles $D_{\text {Blue }}\left(=N_{\text {Blue }} / N_{\text {Total }}\right)$ are $0.39,0.26,0.25$ and 0.25 , and those of red profiles $D_{\text {Red }}$ $\left(=N_{\text {Red }} / N_{\text {Total }}\right)$ are $0.19,0.16,0.40$, and 0.13 in the $\mathrm{HCO}^{+}$ $(1-0), \mathrm{HCO}^{+}(3-2), \mathrm{HCN}(3-2)$, and $\mathrm{H}_{2} \mathrm{CO}\left(2_{12}-1_{11}\right)$ lines, respectively (Table 4$)$. Table 3 presents the estimated values of $\delta v$ and identified profile types for each source in the individual optically thick lines, and Figure 2 exhibits histograms of $\delta v$ for each transition.

We are able to quantify the dominance of blue profile with respect to red profile by the non-dimensional parameter, socalled blue excess $(E)$, introduced by Mardones et al. (1997):

$$
E=\left(N_{\text {Blue }}-N_{\text {Red }}\right) / N_{\text {Total }} \text {. }
$$

Table 4 summarizes our statistical analysis results in four optically thick molecular lines. As mentioned above, the $\mathrm{H}^{13} \mathrm{CO}^{+}(1-0)$ line is used as an optically thin tracer to determine $v_{\text {thin }}$ and $\Delta v_{\text {thin }}$. We found 29 blue profiles and 14 red profiles in the $\mathrm{HCO}^{+}(1-0)$ line for a sample of 74 sources. The blue excess $E$ for the $\mathrm{HCO}^{+}(1-0)$ line is 0.20 . This value is in good agreement with the estimate $(E=0.22)$ obtained by He et al. (2015) for 201 HMPOs in the same transition, and is slightly higher than the estimates of $E=0.15$ acquired by Fuller et al. (2005) for 68 HMPOs and $E=0.17$ by Wu et al. (2007) for 29 HMPOs. We found less significant blue excesses of $E=0.09$ and $E=0.13$ in the $\mathrm{HCO}^{+}(3-2)$ and $\mathrm{H}_{2} \mathrm{CO}\left(2_{12}-1_{11}\right)$ lines, respectively. For comparison, Fuller et al. (2005) obtained $E=0.04$ in the $\mathrm{HCO}^{+}(3-2)$ for 24 sources and $E=0.19$ in the $\mathrm{H}_{2} \mathrm{CO}\left(2_{12}-1_{11}\right)$ for 64 sources.
On the other hand, we found 12 blue and 19 red profiles in the HCN (3-2) line for 48 sources. Thus, our sample shows a quite significant red excess of $E=-0.15$, suggesting that the $\mathrm{HCN}(3-2)$ line traces other dynamics rather than inflows in HMPOs, such as outflow, rotation, and turbulent motions. In contrast, Wu \& Evans (2003) measured a blue excess of 0.21 in the $\mathrm{HCN}(3-2)$ for $28 \mathrm{UCH}$ IIs and compact H II regions, which are mostly more evolved and luminous than the sources in our sample (see Section 4). The molecular tracer appears to have suitable optical depth and critical density for their sample but this is not the case for most sources in our sample.

In order to get rid of the statistical uncertainty coming from the use of different beam sizes of the telescopes, we also obtained statistics of line parameters separately for the ARO $12 \mathrm{~m}$ and the KVN $21 \mathrm{~m}$. That is, we calculated blue excesses of the $\mathrm{HCO}^{+}(1-0)$ line using the $\mathrm{H}^{13} \mathrm{CO}^{+}(1-0)$ line as an optically thin line observed by the same telescope. In case of the ARO $12 \mathrm{~m}$, the numbers of blue and red profiles are 19 and 9 , respectively, out of 45 total sources, which leads to a blue excess of $E=0.22$. On the other hand, in the case of KVN $21 \mathrm{~m}$, the numbers of blue and red profiles are 5 and 2, respectively, for a total of 14 sources, which leads to a blue excess of $E=0.21$. However, the blue excess of the latter case has a statistical weakness arising from the small number of sources. If we combine two observations, the numbers of blue and red profiles are 24 and 11, respectively, for a total of 59 sources and hence the blue excess is $E=0.22$. Thus, our statistics for the entire sample of 74 sources $(E=0.20)$ obtained by the combination of the $\mathrm{HCO}^{+}(1-0)$ and $\mathrm{H}^{13} \mathrm{CO}^{+}(1-0)$ lines detected by different telescopes, seems to be acceptable.

To evaluate the probability that the measured blue excess is produced by coincidence from a random distribution with the same numbers of blue and red profiles, we performed a binomial test (Fuller et al. 2005; Wu et al. 2007; He et al. 2015; Jin et al. 2016) defined as

$$
P(X \geqslant V)=\sum_{x=V}^{N} \frac{N !}{x !(N-x) !} p^{x}(1-p)^{(N-x)} .
$$

Here, $N$ is the number of performances, $V$ is the the number of successes, and $p$ is the probability of occurrence in a single 
Table 3

Line Velocities and Asymmetry Parameters

\begin{tabular}{|c|c|c|c|c|c|c|c|c|c|c|c|c|c|c|c|c|}
\hline \multirow{2}{*}{$\begin{array}{l}\text { IRAS } \\
\text { Name }\end{array}$} & \multicolumn{3}{|c|}{$\mathrm{H}^{13} \mathrm{CO}^{+}(1-0)$} & \multicolumn{4}{|c|}{$v_{\text {thick }}{ }^{\mathrm{a}}$} & \multicolumn{4}{|c|}{$\delta v$} & \multicolumn{4}{|c|}{ Profile } & \multirow[b]{2}{*}{$v_{\text {in }}{ }^{\mathrm{a}}$} \\
\hline & $\tau_{\text {thin }}{ }^{\mathrm{b}}$ & $v\left(v_{\mathrm{err}}\right)^{\mathrm{a}}$ & $\Delta v\left(\Delta v_{\text {err }}\right)^{\mathrm{a}}$ & $\mathrm{L}^{\mathrm{c}}$ & $\mathrm{L} 2^{\mathrm{c}}$ & $\mathrm{L}^{\mathrm{c}}$ & $\mathrm{L}^{\mathrm{c}}$ & L1 & L2 & L3 & L4 & $\mathrm{L} 1$ & $\mathrm{~L} 2$ & L3 & $\overline{\mathrm{L} 4}$ & \\
\hline $00117+6412$ & 0.09 & $-36.21(0.11)$ & $2.32(0.30)$ & -35.46 & -36.44 & -35.63 & -36.20 & 0.32 & -0.10 & 0.25 & 0.00 & $\mathrm{R}$ & $\mathrm{N}$ & $\mathrm{N}$ & $\mathrm{N}$ & $\cdots$ \\
\hline $00420+5530^{*}$ & 0.05 & $-51.44(0.21)$ & $1.41(0.55)$ & -52.04 & -51.34 & -51.71 & -51.80 & -0.43 & 0.07 & -0.20 & -0.26 & B & $\mathrm{N}$ & $\mathrm{N}$ & B & 0.50 \\
\hline $04579+4703^{*}$ & 0.18 & $-16.70(0.08)$ & $1.43(0.20)$ & -16.67 & -16.55 & -17.32 & $\ldots$ & 0.02 & 0.11 & -0.44 & $\ldots$ & $\mathrm{N}$ & $\mathrm{N}$ & B & $\ldots$ & $\ldots$ \\
\hline $05137+3919^{*}$ & 0.05 & $-25.32(0.16)$ & $1.46(0.31)$ & -26.58 & -25.20 & -25.28 & -25.27 & -0.86 & 0.08 & 0.03 & 0.04 & $\mathrm{~B}$ & $\mathrm{~N}$ & $\mathrm{~N}$ & $\mathrm{~N}$ & 0.35 \\
\hline $05168+3634$ & 0.24 & $-15.15(0.06)$ & $1.18(0.18)$ & -15.68 & $\ldots$ & $\ldots$ & -14.73 & -0.45 & $\ldots$ & $\cdots$ & 0.36 & B & $\ldots$ & $\ldots$ & $\mathrm{R}$ & $\ldots$ \\
\hline $05274+3345^{*}$ & 0.21 & $-3.36(0.04)$ & $2.49(0.08)$ & -4.47 & -3.77 & -3.63 & -4.00 & -0.45 & -0.16 & -0.11 & -0.26 & $\mathrm{~B}$ & $\mathrm{~N}$ & $\mathrm{~N}$ & $\mathrm{~B}$ & 0.48 \\
\hline $05345+3157^{*}$ & $\cdots$ & $-18.16(0.17)$ & $1.99(0.33)$ & $\cdots$ & $\cdots$ & $\ldots$ & -18.80 & $\cdots$ & $\cdots$ & $\cdots$ & -0.32 & $\cdots$ & $\cdots$ & $\cdots$ & $\mathrm{B}$ & $\cdots$ \\
\hline $05358+3543$ & 0.07 & $-17.31(0.04)$ & $2.38(0.10)$ & -17.84 & -14.96 & -14.21 & -18.00 & -0.22 & 0.99 & 1.30 & -0.29 & $\mathrm{~N}$ & $\mathrm{R}$ & $\mathrm{R}$ & B & $\ldots$ \\
\hline $05373+2349$ & 0.32 & $2.23(0.03)$ & $1.66(0.08)$ & 1.95 & $\ldots$ & 2.79 & 2.00 & -0.17 & $\ldots$ & 0.34 & -0.14 & $\mathrm{~N}$ & $\ldots$ & $\mathrm{R}$ & $\mathrm{N}$ & $\ldots$ \\
\hline 05391-0152 & 0.16 & $9.91(0.04)$ & $1.21(0.10)$ & 9.16 & 10.89 & 11.03 & 10.53 & -0.62 & 0.81 & 0.93 & 0.52 & B & $\mathrm{R}$ & $\mathrm{R}$ & $\mathrm{R}$ & $\cdots$ \\
\hline 05393-0156 & 0.09 & $10.13(0.07)$ & $2.06(0.16)$ & 9.16 & 11.10 & 11.03 & 10.96 & -0.47 & 0.47 & 0.44 & 0.40 & B & $\mathrm{R}$ & $\mathrm{R}$ & $\mathrm{R}$ & \\
\hline $05490+2658^{*}$ & 0.13 & $0.55(0.07)$ & $1.24(0.19)$ & 0.11 & $\ldots$ & 0.33 & 0.73 & -0.36 & $\ldots$ & -0.18 & 0.15 & $\mathrm{~B}$ & $\ldots$ & $\mathrm{N}$ & $\mathrm{N}$ & 0.50 \\
\hline $05553+1631$ & 0.12 & $5.65(0.05)$ & $1.90(0.12)$ & 6.37 & $\ldots$ & 5.29 & 5.47 & 0.38 & $\ldots$ & -0.19 & -0.10 & $\mathrm{R}$ & $\ldots$ & $\mathrm{N}$ & $\mathrm{N}$ & $\ldots$ \\
\hline $06053-0622$ & 0.07 & $10.49(0.08)$ & $2.64(0.22)$ & 9.83 & 10.45 & 10.59 & 9.89 & -0.25 & -0.01 & 0.04 & -0.23 & $\mathrm{~N}$ & $\mathrm{~N}$ & $\mathrm{~N}$ & $\mathrm{~N}$ & $\ldots$ \\
\hline $06056+2131$ & 0.10 & $2.54(0.03)$ & $2.22(0.06)$ & 2.53 & 2.81 & $\ldots$ & 2.73 & 0.00 & 0.12 & $\ldots$ & 0.09 & $\mathrm{~N}$ & $\mathrm{~N}$ & $\ldots$ & $\mathrm{N}$ & $\ldots$ \\
\hline $06061+2151$ & 0.13 & $-0.88(0.08)$ & $2.02(0.19)$ & -1.05 & $\ldots$ & -0.02 & -1.00 & -0.08 & $\ldots$ & 0.43 & -0.06 & $\mathrm{~N}$ & $\ldots$ & $\mathrm{R}$ & $\mathrm{N}$ & $\ldots$ \\
\hline 06084-0611 & 0.13 & $11.59(0.06)$ & $1.98(0.14)$ & 11.85 & 11.10 & 11.25 & 11.60 & 0.13 & -0.25 & -0.17 & 0.00 & $\mathrm{~N}$ & $\mathrm{~N}$ & $\mathrm{~N}$ & $\mathrm{~N}$ & $\ldots$ \\
\hline $06103+1523$ & 0.09 & $15.57(0.05)$ & $1.87(0.11)$ & 16.37 & $\ldots$ & 16.76 & 16.27 & 0.43 & $\ldots$ & 0.64 & 0.37 & $\mathrm{R}$ & $\ldots$ & $\mathrm{R}$ & $\mathrm{R}$ & $\ldots$ \\
\hline $06105+1756^{*}$ & 0.04 & $7.78(0.14)$ & $1.32(0.36)$ & 7.24 & $\ldots$ & 7.46 & $\ldots$ & -0.41 & $\ldots$ & -0.24 & $\ldots$ & B & $\ldots$ & $\mathrm{N}$ & $\ldots$ & 0.28 \\
\hline $06382+0939$ & 0.33 & $5.22(0.02)$ & $2.13(0.06)$ & 4.70 & $\cdots$ & 4.94 & 5.31 & -0.24 & $\ldots$ & -0.13 & 0.04 & $\mathrm{~N}$ & $\ldots$ & $\mathrm{N}$ & $\mathrm{N}$ & $\cdots$ \\
\hline 06584-0852 & $\cdots$ & $\cdots(\cdots)$ & $\cdots(\cdots)$ & 41.13 & $\ldots$ & $\cdots$ & $\cdots$ & $\cdots$ & $\ldots$ & $\cdots$ & $\ldots$ & $\ldots$ & $\ldots$ & $\ldots$ & $\ldots$ & $\cdots$ \\
\hline $07299-1651$ & 0.08 & $17.18(0.11)$ & $1.78(0.30)$ & 17.48 & 17.22 & 17.77 & 17.34 & 0.17 & 0.02 & 0.34 & 0.09 & $\mathrm{~N}$ & $\mathrm{~N}$ & $\mathrm{R}$ & $\mathrm{N}$ & $\ldots$ \\
\hline $07427-2400^{*}$ & 0.12 & $67.82(0.25)$ & $4.88(0.58)$ & 66.13 & 67.22 & 69.06 & 68.67 & -0.35 & -0.12 & 0.25 & 0.17 & $\mathrm{~B}$ & $\mathrm{~N}$ & $\mathrm{~N}$ & $\mathrm{~N}$ & 0.42 \\
\hline $17417-2851^{*}$ & 0.08 & $-5.33(0.17)$ & $2.77(0.42)$ & -6.44 & -5.46 & -6.30 & -6.13 & -0.40 & -0.05 & -0.35 & -0.29 & $\mathrm{~B}$ & $\mathrm{~N}$ & $\mathrm{~B}$ & $\mathrm{~B}$ & 0.68 \\
\hline $17450-2742$ & $\ldots$ & $\cdots(\cdots)$ & $\cdots(\cdots)$ & -16.06 & -15.64 & $\ldots$ & -15.73 & $\ldots$ & $\ldots$ & $\ldots$ & $\ldots$ & $\ldots$ & $\ldots$ & $\ldots$ & $\ldots$ & $\ldots$ \\
\hline $17504-2519^{*}$ & 0.18 & $12.65(0.06)$ & $1.38(0.13)$ & 11.56 & 11.70 & 12.97 & 12.08 & -0.79 & -0.69 & 0.23 & -0.42 & B & B & $\mathrm{N}$ & B & 1.26 \\
\hline $17527-2439$ & 0.17 & $13.52(0.13)$ & $2.21(0.35)$ & 14.04 & $\ldots$ & $\ldots$ & 13.95 & 0.24 & $\ldots$ & $\ldots$ & 0.19 & $\mathrm{~N}$ & $\ldots$ & $\ldots$ & $\mathrm{N}$ & $\ldots$ \\
\hline $18014-2428$ & $\ldots$ & $\cdots(\cdots)$ & $\cdots(\cdots)$ & 12.67 & 12.64 & $\ldots$ & 12.39 & $\ldots$ & $\ldots$ & $\ldots$ & $\ldots$ & $\ldots$ & $\ldots$ & $\ldots$ & $\ldots$ & $\ldots$ \\
\hline $18018-2426$ & 0.07 & $10.92(0.08)$ & $1.92(0.19)$ & 10.67 & 11.48 & $\ldots$ & 10.82 & -0.13 & 0.29 & $\ldots$ & -0.05 & $\mathrm{~N}$ & $\mathrm{R}$ & $\ldots$ & $\mathrm{N}$ & $\ldots$ \\
\hline $18024-2119$ & $\ldots$ & $0.39(0.05)$ & $2.14(0.11)$ & $\ldots$ & $\ldots$ & $\cdots$ & $\ldots$ & $\ldots$ & $\ldots$ & $\ldots$ & $\ldots$ & $\ldots$ & $\ldots$ & $\ldots$ & $\ldots$ & $\ldots$ \\
\hline $18089-1732$ & 0.21 & $33.41(0.13)$ & $3.40(0.30)$ & 35.43 & $\ldots$ & 29.75 & 34.35 & 0.59 & $\ldots$ & -1.08 & 0.28 & $\mathrm{R}$ & $\ldots$ & B & $\mathrm{R}$ & $\ldots$ \\
\hline 18134-1942 & 0.19 & $10.38(0.05)$ & $1.70(0.11)$ & 11.00 & 10.92 & 11.10 & 10.61 & 0.37 & 0.32 & 0.43 & 0.14 & $\mathrm{R}$ & $\mathrm{R}$ & $\mathrm{R}$ & $\mathrm{N}$ & $\cdots$ \\
\hline $18144-1723$ & 0.08 & $48.23(0.16)$ & $3.00(0.37)$ & 48.81 & 48.84 & 50.57 & 48.47 & 0.19 & 0.20 & 0.78 & 0.08 & $\mathrm{~N}$ & $\mathrm{~N}$ & $\mathrm{R}$ & $\mathrm{N}$ & $\ldots$ \\
\hline $18151-1208$ & 0.06 & $32.96(0.16)$ & $2.96(0.42)$ & 32.63 & 32.94 & $\ldots$ & 32.69 & -0.11 & -0.01 & $\cdots$ & -0.09 & $\mathrm{~N}$ & $\mathrm{~N}$ & $\mathrm{~N}$ & $\ldots$ & \\
\hline $18159-1550$ & 0.14 & $59.21(0.12)$ & $2.86(0.31)$ & 60.88 & 59.56 & 60.58 & 60.23 & 0.58 & 0.12 & 0.48 & 0.36 & $\mathrm{R}$ & $\mathrm{N}$ & $\mathrm{R}$ & $\mathrm{R}$ & $\ldots$ \\
\hline $18159-1648$ & 0.24 & $22.38(0.07)$ & $3.43(0.15)$ & 24.62 & 21.68 & 25.39 & 23.06 & 0.65 & -0.20 & 0.88 & 0.20 & $\mathrm{R}$ & $\mathrm{N}$ & $\mathrm{R}$ & $\mathrm{N}$ & $\cdots$ \\
\hline $18162-1612$ & 0.06 & $61.85(0.14)$ & $1.73(0.31)$ & 61.63 & $\ldots$ & $\ldots$ & 61.69 & -0.12 & $\cdots$ & $\cdots$ & -0.09 & $\mathrm{~N}$ & $\cdots$ & $\cdots$ & $\mathrm{N}$ & $\cdots$ \\
\hline $18236-1205^{*}$ & 0.24 & $26.90(0.12)$ & $3.20(0.26)$ & 25.02 & $\ldots$ & $\ldots$ & 25.67 & -0.59 & $\ldots$ & $\ldots$ & -0.38 & B & $\ldots$ & $\ldots$ & B & 1.65 \\
\hline $18256-0742^{*}$ & 0.15 & $36.82(0.10)$ & $1.27(0.21)$ & 36.20 & $\cdots$ & $\cdots$ & 35.96 & -0.49 & $\cdots$ & $\cdots$ & -0.68 & $\mathrm{~B}$ & $\cdots$ & $\cdots$ & $\mathrm{B}$ & 0.40 \\
\hline $18258-0737$ & 0.05 & $37.27(0.40)$ & $2.93(1.03)$ & 38.40 & $\cdots$ & 38.78 & 38.43 & 0.39 & $\cdots$ & 0.52 & 0.40 & $\mathrm{R}$ & $\ldots$ & $\mathrm{R}$ & $\mathrm{R}$ & $\ldots$ \\
\hline $18316-0602$ & 0.26 & $42.46(0.07)$ & $3.38(0.20)$ & 41.36 & 42.06 & 44.71 & 41.88 & -0.32 & -0.12 & 0.67 & -0.17 & B & $\mathrm{N}$ & $\mathrm{R}$ & $\mathrm{N}$ & $\ldots$ \\
\hline $18317-0513$ & 0.08 & $42.27(0.08)$ & $1.33(0.22)$ & 42.03 & 42.06 & $\ldots$ & 42.09 & -0.18 & -0.16 & $\ldots$ & -0.13 & $\mathrm{~N}$ & $\mathrm{~N}$ & $\mathrm{~N}$ & $\ldots$ & \\
\hline $18360-0537^{*}$ & 0.10 & $101.71(0.71)$ & $4.16(0.37)$ & 100.45 & 101.04 & 99.71 & 101.13 & -0.30 & -0.16 & -0.48 & -0.14 & $\mathrm{~B}$ & $\mathrm{~N}$ & $\mathrm{~B}$ & $\mathrm{~N}$ & 2.00 \\
\hline $18372-0541$ & $\cdots$ & $22.93(0.11)$ & $2.70(0.25)$ & $\cdots$ & $\cdots$ & $\cdots$ & $\cdots$ & $\cdots$ & $\cdots$ & $\cdots$ & $\cdots$ & $\cdots$ & $\cdots$ & $\cdots$ & $\cdots$ & $\ldots$ \\
\hline $18396-0431$ & 0.14 & $97.22(0.08)$ & $1.80(0.18)$ & 98.48 & $\cdots$ & $\cdots$ & $\cdots$ & 0.70 & $\cdots$ & $\cdots$ & $\cdots$ & $\mathrm{R}$ & $\cdots$ & $\cdots$ & $\cdots$ & $\cdots$ \\
\hline $18488+0000$ & 0.33 & $83.15(0.06)$ & $2.56(0.16)$ & 81.48 & 82.78 & 84.84 & 81.67 & -0.65 & -0.15 & 0.66 & -0.58 & $\mathrm{~B}$ & $\mathrm{~N}$ & $\mathrm{R}$ & $\mathrm{B}$ & $\cdots$ \\
\hline $18507+0121$ & 0.36 & $57.46(0.07)$ & $4.06(0.17)$ & 59.96 & 58.64 & $\cdots$ & 56.99 & 0.62 & 0.29 & $\cdots$ & -0.11 & $\mathrm{R}$ & $\mathrm{R}$ & $\cdots$ & $\mathrm{N}$ & $\cdots$ \\
\hline
\end{tabular}


Table 3

(Continued)

\begin{tabular}{|c|c|c|c|c|c|c|c|c|c|c|c|c|c|c|c|c|}
\hline \multirow{2}{*}{$\begin{array}{l}\text { IRAS } \\
\text { Name }\end{array}$} & \multicolumn{3}{|c|}{$\mathrm{H}^{13} \mathrm{CO}^{+}(1-0)$} & \multicolumn{4}{|c|}{$v_{\text {thick }}{ }^{\mathrm{a}}$} & \multicolumn{4}{|c|}{$\delta v$} & \multicolumn{4}{|c|}{ Profile } & \multirow[b]{2}{*}{$v_{\text {in }}{ }^{\mathrm{a}}$} \\
\hline & $\tau_{\text {thin }}{ }^{\mathrm{b}}$ & $v\left(v_{\text {err }}\right)^{\mathrm{a}}$ & $\Delta v\left(\Delta v_{\text {err }}\right)^{\mathrm{a}}$ & $\mathrm{L}^{\mathrm{c}}$ & $\mathrm{L} 2^{\mathrm{c}}$ & $\mathrm{L}^{\mathrm{c}}$ & $\mathrm{L}^{\mathrm{c}}$ & L1 & L2 & L3 & L4 & $\mathrm{L} 1$ & L2 & L3 & $\overline{\mathrm{L} 4}$ & \\
\hline $18511+0146$ & 0.18 & $57.70(0.13)$ & $2.97(0.30)$ & 59.99 & $\cdots$ & $\cdots$ & 57.55 & 0.77 & $\cdots$ & $\cdots$ & -0.05 & $\mathrm{R}$ & $\cdots$ & $\cdots$ & $\mathrm{N}$ & $\cdots$ \\
\hline $18527+0301^{*}$ & 0.16 & $76.05(0.10)$ & $1.88(0.26)$ & 75.50 & $\ldots$ & $\ldots$ & 75.47 & -0.30 & $\ldots$ & $\ldots$ & -0.31 & B & $\ldots$ & $\ldots$ & B & 0.80 \\
\hline $18532+0047$ & 0.24 & $58.77(0.07)$ & $2.50(0.16)$ & 58.95 & $\ldots$ & $\ldots$ & 59.27 & 0.07 & $\ldots$ & $\cdots$ & 0.20 & $\mathrm{~N}$ & $\ldots$ & $\ldots$ & $\mathrm{N}$ & $\ldots$ \\
\hline $18565+0349^{*}$ & 0.10 & $91.42(0.13)$ & $2.26(0.29)$ & 90.76 & 91.18 & $\ldots$ & 91.49 & -0.29 & -0.11 & $\ldots$ & 0.03 & B & $\mathrm{N}$ & $\ldots$ & $\mathrm{N}$ & 1.40 \\
\hline $18566+0408$ & 0.13 & $85.52(0.21)$ & $3.72(0.52)$ & 82.58 & $\cdots$ & $\cdots$ & 87.34 & -0.79 & $\cdots$ & $\cdots$ & 0.49 & B & $\cdots$ & $\cdots$ & $\mathrm{R}$ & $\cdots$ \\
\hline $18567+0700$ & 0.20 & $29.52(0.05)$ & $1.20(0.14)$ & 29.57 & $\cdots$ & $\cdots$ & 29.29 & 0.04 & $\cdots$ & $\cdots$ & -0.18 & $\mathrm{~N}$ & $\cdots$ & $\cdots$ & $\mathrm{N}$ & $\cdots$ \\
\hline $19045+0518$ & 0.10 & $53.72(0.10)$ & $1.88(0.41)$ & 53.43 & $\cdots$ & 53.26 & 53.49 & -0.16 & $\cdots$ & -0.24 & -0.12 & $\mathrm{~N}$ & $\ldots$ & $\mathrm{N}$ & $\mathrm{N}$ & $\cdots$ \\
\hline $19088+0902$ & 0.17 & $59.92(0.19)$ & $2.00(0.46)$ & 61.45 & $\cdots$ & 57.73 & 59.28 & 0.77 & $\cdots$ & -1.10 & -0.32 & $\mathrm{R}$ & $\cdots$ & B & B & $\cdots$ \\
\hline $19282+1814^{*}$ & 0.11 & $24.18(0.09)$ & $0.95(0.24)$ & 23.60 & $\cdots$ & $\cdots$ & 23.78 & -0.61 & $\cdots$ & $\cdots$ & -0.42 & B & $\cdots$ & $\cdots$ & $\mathrm{B}$ & 0.23 \\
\hline $19368+2239^{*}$ & 0.10 & $36.51(0.12)$ & $2.29(0.28)$ & 36.23 & 35.70 & 35.68 & 36.29 & -0.12 & -0.36 & -0.36 & -0.10 & $\mathrm{~N}$ & $\mathrm{~B}$ & B & $\mathrm{N}$ & $\ldots$ \\
\hline $20050+2720$ & 0.24 & $6.10(0.07)$ & $1.98(0.18)$ & 4.22 & 5.42 & 7.20 & 5.23 & -0.95 & -0.34 & 0.56 & -0.44 & B & $\mathrm{B}$ & $\mathrm{R}$ & $\mathrm{B}$ & $\ldots$ \\
\hline $20056+3350^{*}$ & 0.09 & $9.33(0.17)$ & $2.05(0.46)$ & 9.57 & 8.42 & 8.12 & 8.87 & 0.12 & -0.44 & -0.59 & -0.22 & $\mathrm{~N}$ & $\mathrm{~B}$ & B & $\mathrm{N}$ & $\cdots$ \\
\hline $20062+3550^{*}$ & 0.11 & $0.81(0.14)$ & $1.31(0.33)$ & 0.77 & 1.02 & 0.88 & 0.28 & -0.03 & 0.16 & 0.06 & -0.40 & $\mathrm{~N}$ & $\mathrm{~N}$ & $\mathrm{~N}$ & B & $\ldots$ \\
\hline $20106+3545^{*}$ & 0.08 & $8.08(0.09)$ & $1.64(0.23)$ & 7.63 & $\cdots$ & $\ldots$ & 7.91 & -0.27 & $\cdots$ & $\cdots$ & -0.11 & B & $\ldots$ & $\cdots$ & $\mathrm{N}$ & 0.25 \\
\hline 20126+4104 & 0.10 & $-3.36(0.07)$ & $2.29(0.18)$ & -3.40 & -3.20 & -3.01 & -3.58 & -0.01 & 0.07 & 0.16 & -0.09 & $\mathrm{~N}$ & $\mathrm{~N}$ & $\mathrm{~N}$ & $\mathrm{~N}$ & $\ldots$ \\
\hline $20188+3928$ & 0.18 & $1.77(0.09)$ & $2.08(0.19)$ & 2.68 & 2.20 & 2.76 & 2.46 & 0.43 & 0.21 & 0.48 & 0.33 & $\mathrm{R}$ & $\mathrm{N}$ & $\mathrm{R}$ & $\mathrm{R}$ & $\ldots$ \\
\hline $20220+3728^{*}$ & 0.04 & $-1.89(0.23)$ & $3.40(0.56)$ & -2.87 & -3.68 & -4.20 & -2.81 & -0.29 & -0.53 & -0.68 & -0.27 & B & B & B & B & 0.47 \\
\hline $20227+4154$ & 0.21 & $5.84(0.07)$ & $1.43(0.15)$ & 6.40 & $\cdots$ & $\cdots$ & 5.58 & 0.39 & $\cdots$ & $\cdots$ & -0.18 & $\mathrm{R}$ & $\ldots$ & $\cdots$ & $\mathrm{N}$ & $\cdots$ \\
\hline $20278+3521$ & 0.05 & $-3.99(0.18)$ & $2.71(0.44)$ & -4.67 & $\cdots$ & $\cdots$ & -4.61 & -0.25 & $\cdots$ & $\cdots$ & -0.23 & $\mathrm{~N}$ & $\ldots$ & $\ldots$ & $\mathrm{N}$ & $\ldots$ \\
\hline $20286+4105^{*}$ & 0.06 & $-3.70(0.12)$ & $3.89(0.31)$ & -4.30 & -4.78 & -4.73 & -4.97 & -0.16 & -0.28 & -0.27 & -0.33 & $\mathrm{~N}$ & $\mathrm{~B}$ & B & B & $\cdots$ \\
\hline $20333+4102^{*}$ & 0.07 & $8.64(0.05)$ & $1.25(0.12)$ & 8.57 & 8.26 & 8.57 & 8.51 & -0.05 & -0.30 & -0.05 & -0.10 & $\mathrm{~N}$ & $\mathrm{~B}$ & $\mathrm{~N}$ & $\mathrm{~N}$ & $\cdots$ \\
\hline $21078+5211$ & $\ldots$ & $\cdots(\cdots)$ & $\cdots(\cdots)$ & -6.60 & -6.80 & -6.88 & -6.42 & $\cdots$ & $\ldots$ & $\ldots$ & $\ldots$ & $\cdots$ & $\ldots$ & $\cdots$ & $\ldots$ & $\ldots$ \\
\hline $21391+5802^{*}$ & 0.27 & $0.65(0.04)$ & $1.97(0.11)$ & -0.44 & -0.30 & -0.16 & 0.08 & -0.55 & -0.48 & -0.41 & -0.29 & B & B & B & B & 1.10 \\
\hline $21519+5613$ & $\cdots$ & $\cdots(\cdots)$ & $\cdots(\cdots)$ & -62.70 & -63.06 & -62.68 & -62.88 & $\cdots$ & $\cdots$ & $\cdots$ & $\cdots$ & $\cdots$ & $\cdots$ & $\cdots$ & $\cdots$ & $\cdots$ \\
\hline $22172+5549$ & 0.09 & $-43.56(0.10)$ & $2.78(0.28)$ & -43.63 & -43.38 & -43.15 & -43.48 & -0.03 & 0.06 & 0.15 & 0.03 & $\mathrm{~N}$ & $\mathrm{~N}$ & $\mathrm{~N}$ & $\mathrm{~N}$ & $\cdots$ \\
\hline $22198+6336$ & 0.11 & $-11.00(0.13)$ & $1.48(0.25)$ & -11.60 & -11.52 & -9.93 & -11.42 & -0.41 & -0.35 & 0.72 & -0.28 & B & $\mathrm{B}$ & $\mathrm{R}$ & B & $\ldots$ \\
\hline $22267+6244$ & 0.16 & $-1.32(0.07)$ & $1.51(0.15)$ & -2.00 & -1.92 & 0.07 & -1.39 & -0.45 & -0.40 & 0.92 & -0.05 & B & $\mathrm{B}$ & $\mathrm{R}$ & $\mathrm{N}$ & $\cdots$ \\
\hline $22272+6358^{*}$ & 0.14 & $-9.95(0.06)$ & $1.11(0.13)$ & -10.40 & -10.88 & -10.54 & -10.01 & -0.41 & -0.84 & -0.53 & -0.05 & B & $\mathrm{B}$ & B & $\mathrm{N}$ & 0.47 \\
\hline $22308+5812$ & 0.04 & $-52.29(0.23)$ & $5.08(0.66)$ & -53.41 & $\cdots$ & $\cdots$ & -52.93 & -0.22 & $\cdots$ & $\cdots$ & -0.13 & $\mathrm{~N}$ & $\cdots$ & $\cdots$ & $\mathrm{N}$ & $\cdots$ \\
\hline $22506+5944$ & 0.19 & $-51.46(0.05)$ & $2.08(0.14)$ & -51.33 & -50.52 & -49.51 & $\cdots$ & 0.06 & 0.45 & 0.94 & $\cdots$ & $\mathrm{N}$ & $\mathrm{R}$ & $\mathrm{R}$ & $\cdots$ & $\cdots$ \\
\hline $23026+5948$ & 0.04 & $-51.10(0.12)$ & $1.77(0.29)$ & -51.27 & $\cdots$ & $\cdots$ & -51.42 & -0.10 & $\cdots$ & $\cdots$ & -0.18 & $\mathrm{~N}$ & $\cdots$ & $\cdots$ & $\mathrm{N}$ & $\cdots$ \\
\hline $23133+6050$ & 0.04 & $-56.55(0.08)$ & $2.61(0.23)$ & -56.48 & $\cdots$ & $\cdots$ & -56.27 & 0.03 & $\cdots$ & $\cdots$ & 0.11 & $\mathrm{~N}$ & $\cdots$ & $\cdots$ & $\mathrm{N}$ & $\cdots$ \\
\hline $23140+6121^{*}$ & 0.15 & $-51.27(0.08)$ & $1.77(0.17)$ & -52.00 & $\cdots$ & $\cdots$ & -51.61 & -0.41 & $\cdots$ & $\cdots$ & -0.19 & B & $\cdots$ & $\cdots$ & $\mathrm{N}$ & 1.47 \\
\hline $23314+6033$ & 0.06 & $-45.24(0.14)$ & $2.41(0.40)$ & -45.23 & $\ldots$ & $\cdots$ & -45.53 & 0.00 & $\cdots$ & $\ldots$ & -0.12 & $\mathrm{~N}$ & $\ldots$ & $\ldots$ & $\mathrm{N}$ & $\ldots$ \\
\hline $23545+6508^{*}$ & 0.14 & $-18.47(0.06)$ & $1.15(0.16)$ & -19.58 & -18.54 & -18.76 & -18.72 & -0.96 & -0.06 & -0.26 & -0.22 & B & $\mathrm{N}$ & B & $\mathrm{N}$ & 0.23 \\
\hline
\end{tabular}

Notes.

${ }^{\mathrm{a}}$ In units of $\mathrm{km} \mathrm{s}^{-1}$.

${ }^{\mathrm{b}}$ Optical depth for the $\mathrm{H}^{13} \mathrm{CO}^{+}(1-0)$ line.

${ }^{\mathrm{c}} \mathrm{L} 1: \mathrm{HCO}^{+}(1-0), \mathrm{L}^{2}: \mathrm{HCO}^{+}(3-2), \mathrm{L} 3: \mathrm{HCN}(3-2), \mathrm{L} 4: \mathrm{H}_{2} \mathrm{CO}\left(2_{12}-1_{11}\right)$. 

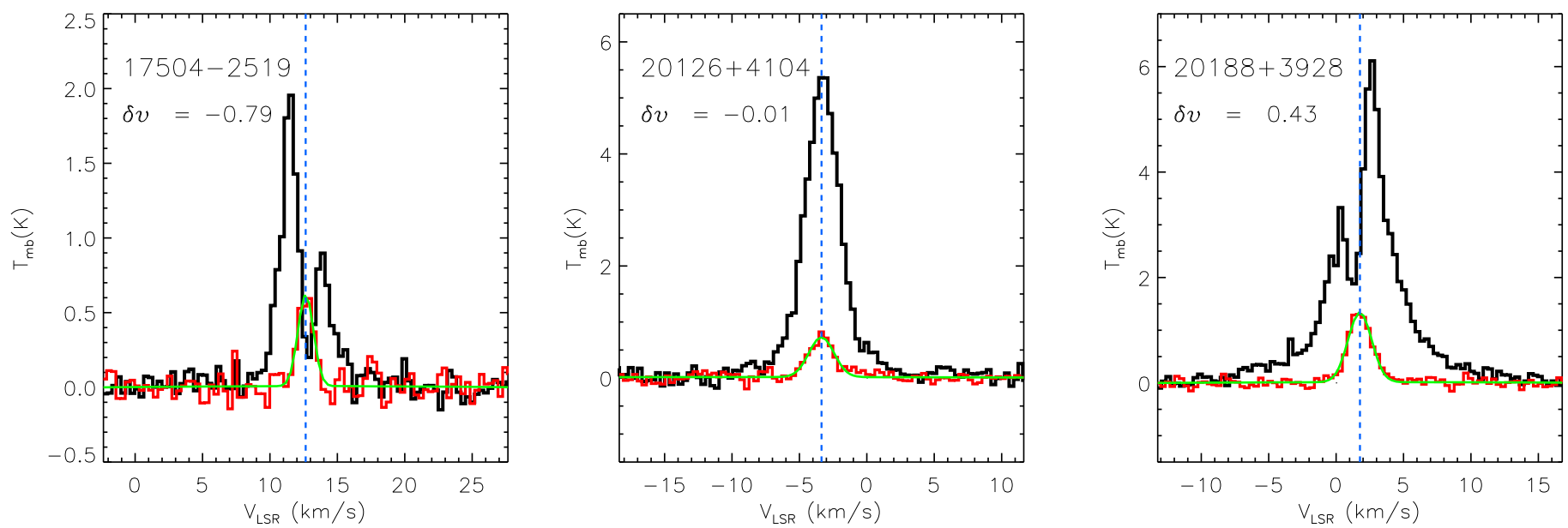

Figure 1. Spectra for representative B profiles (left), $\mathrm{N}$ profiles (middle), and R profiles (right). In each panel, the red and black solid lines show the $\mathrm{HCO}^{+}(1-0)$ and $\mathrm{H}^{13} \mathrm{CO}^{+}(1-0)$ line profiles, respectively. The blue dotted vertical line indicates the peak velocity of the $\mathrm{H}^{13} \mathrm{CO}^{+}(1-0)$ line from the Gaussian fitting result in green. The IRAS name and the estimated $\delta v$ are presented in the top left corner (Table 3).

Table 4

Blue Excess Statistics for the Entire Sample

\begin{tabular}{lcccccr}
\hline \hline Transition & $N_{\text {Blue }}$ & $N_{\text {Red }}$ & $N_{\text {Total }}$ & $D_{\text {Blue }}$ & $D_{\text {Red }}$ & $E$ \\
\hline $\mathrm{HCO}^{+}(1-0)$ & 29 & 14 & 74 & 0.39 & 0.19 & 0.16 \\
$\mathrm{HCO}^{+}(3-2)$ & 11 & 7 & 43 & 0.26 & 0.16 & 0.09 \\
$\mathrm{HCN}(3-2)$ & 12 & 19 & 48 & 0.25 & 0.40 & -0.15 \\
$\mathrm{H}_{2} \mathrm{CO}\left(2_{12}-1_{11}\right)$ & 18 & 9 & 71 & 0.25 & 0.13 & 0.13 \\
\hline
\end{tabular}

independent performance. In our case, $N$ is the total number of blue and red profiles and $V$ is the number of blue profiles. Table 4 also lists the derived values of $P$. The $P$ value for the $\mathrm{HCO}^{+}(1-0)$ line is 0.016 , which implies that the estimated blue excess $(E=0.20)$ is very unlikely to be generated by chance from an even distribution.

\subsection{Inflow Candidates}

Since the sources in our sample were observed in multiple optically thick lines, one source can be classified as different profile types in different transitions. We thus identified strong inflow candidates, similar to some previous studies, using the two criteria: (1) at least one blue (B) profile and (2) no red (R) profile (e.g., Mardones et al. 1997; Fuller et al. 2005). There are 27 sources satisfying these criteria. The inflow candidates are marked with asterisks in the first column of Table 3 (see also Figure 4 in the Appendix). Three of them (IRAS 05490+2658, IRAS $19282+1814$, IRAS $23545+6508$ ) had been observed by Fuller et al. (2005) as well, but only IRAS $05490+2658$ was identified as an inflow candidate, while the other two did not show any line asymmetry (see their Table 9). In reality, their observed positions are offset from ours by $12^{\prime \prime}, 76^{\prime \prime}$, and $23^{\prime \prime}$ for IRAS $05490+2658$, IRAS 19282+1814, and IRAS 23545 +6508 , respectively. The large offsets can cause the nondetection of blue asymmetry in their line profiles of $\mathrm{HCO}^{+}$ $(1-0)$ and $\mathrm{H}_{2} \mathrm{CO}\left(2_{12}-1_{11}\right)$ for IRAS $19282+1814$ and IRAS $23545+6508$, taking into account their beam sizes of $29^{\prime \prime}$ at $89 \mathrm{GHz}$ and $17^{\prime \prime}$ at $140 \mathrm{GHz}$. Therefore, all 27 sources but IRAS $05490+2658$ are newly identified inflow candidates. It should be noted that the HCN (3-2) spectrum of IRAS 04579
+4703 and the $\mathrm{H}_{2} \mathrm{CO}\left(2_{12}-1_{11}\right)$ spectrum of IRAS 05345 +3157 are quite noisy (Figure 4 ), so their classifications as blue profiles need to be confirmed by more sensitive observations.

We derived the inflow velocities, $v_{\text {in }}$, for 20 inflow candidates with blue $\mathrm{HCO}^{+}(1-0)$ line profiles using the two-layer radiative transfer model of Myers et al. (1996). The model assumes two uniform layers approaching each other with different excitation temperatures. The inflow velocity is determined by both optical depth and excitation temperature. The estimated inflow velocities range from 0.23 to $2.00 \mathrm{~km} \mathrm{~s}^{-1}$ with a median value of $0.49 \mathrm{~km} \mathrm{~s}^{-1}$ (Table 3$)$. These values are comparable to the estimates $\left(0.1-1.8 \mathrm{~km} \mathrm{~s}^{-1}\right)$ of Klaassen \& Wilson (2007) for eight high-mass star-forming clumps. For further detailed studies, including measurements of the inflow region size and the inflow mass rate, the mapping observations of the blue profiles are required.

On the other hand, we also found 18 sources that have at least 1 red profile and no blue profile. It is likely that the profiles might be affected by dynamics other than inflow motion. There are 12 sources with both blue and red profiles. They are all classified as High sources, and 7 of them show blue profiles in the $\mathrm{HCO}^{+}(1-0)$ transition but red profiles in the $\mathrm{HCN}(3-2)$ transition.

\section{Discussion}

Our sample is divided into two groups (Low and High) in the IRAS color-color diagram of [25-12] and [60-12], as discussed in Section 2.1. The sources in the High group are believed to be in a relatively more evolved stage than those of the Low group, although the two groups have similar distributions of infrared 

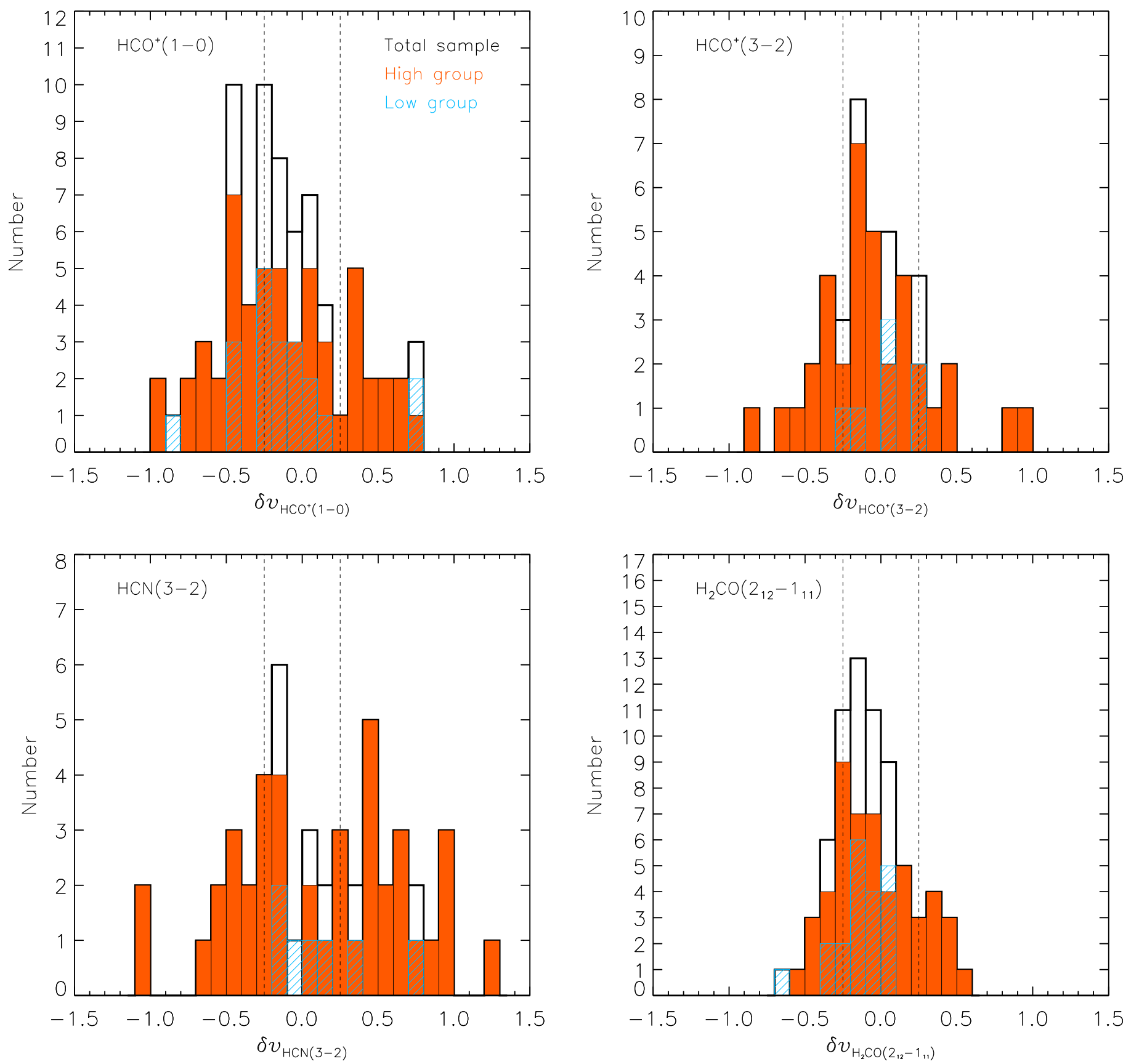

Figure 2. Histograms of $\delta v$ for the observed optically thick lines: $\mathrm{HCO}^{+}(1-0), \mathrm{HCO}^{+}(3-2), \mathrm{HCN}(3-2)$, and $\mathrm{H}_{2} \mathrm{CO}\left(2_{12}-1_{11}\right)$. The black solid lines are for the entire sample, while the orange-colored bars and the cyan hatched bars are for the High and Low groups, respectively. The vertical dotted lines indicate the threshold values of $\delta v, \pm 0.25$

luminosities (Palla et al. 1991; Molinari et al. 1996, 1998). We derive blue excesses separately for the Low and High groups. Table 5 presents the statistical results in all the optically thick transitions (see also Figure 2) and Figure 3 shows the distributions of blue- and red-profile sources in the two groups on the color-color diagram. In comparison with the High group, the Low group shows higher blue excesses in the $\mathrm{HCO}^{+}$ $(1-0)$ and $\mathrm{H}_{2} \mathrm{CO}\left(2_{12}-1_{11}\right)$ lines but lower excesses in the $\mathrm{HCO}^{+}(3-2)$ and $\mathrm{HCN}(3-2)$ lines. In the case of the Low group, however, it should be noted that only the $\mathrm{HCO}^{+}(1-0)$ and $\mathrm{H}_{2} \mathrm{CO}\left(2_{12}-1_{11}\right)$ lines have statistically sufficient numbers of sources, so the blue excess estimates of the $\mathrm{HCO}^{+}(3-2)$ and HCN (3-2) lines may not be meaningful. Thus, further observations for a substantially large number of sources are required for the latter transitions to obtain more significant results for evolutionary study of inflow.

There are very few previous studies investigating the evolutionary effect in the inflow statistics, the results of which are inconclusive. Wu et al. (2007) reported a higher blue excess for 12 UCH IIs $(E=0.58)$ than 29 HMPOs $(E=0.17)$ in the $\mathrm{HCO}^{+}(1-0)$ transition. Jin et al. (2016) also found a similar increasing trend in the $\mathrm{HCN}$ (1-0) line for their sample 

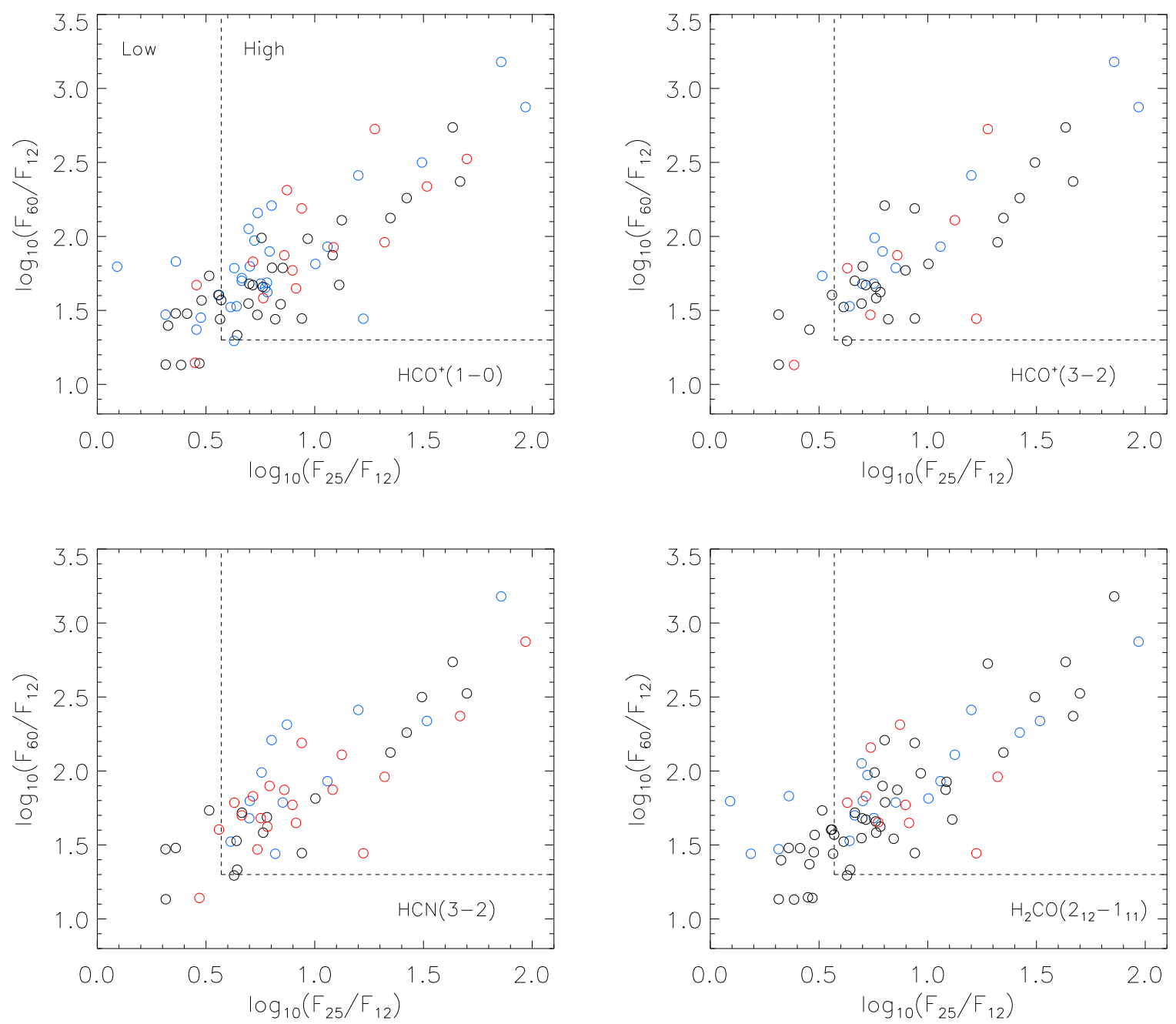

Figure 3. IRAS color-color diagrams of [25-12] vs. [60-12] for the optically thick lines. The dotted lines are the IRAS color criteria of Wood \& Churchwell (1989) for UCH II candidates (High sources), [25-12] $\geqq 0.57$ and [60-12] $\geqq 1.30$. The blue, red, and black open circles represent blue, red, and neutral profiles in each line, respectively.

consisting of 26 HMPOs $(E=0.15)$ and 23 UCH IIs $(E=0.30)$, although they obtained the highest blue excess $(E=0.42)$ for 12 high-mass prestellar clumps. On the contrary, He et al. (2015) found a decreasing evolutionary trend of blue excess in the $\mathrm{HCO}^{+}(1-0)$ line for a much larger sample: $E=0.29$ for 84 prestellar clumps, 0.22 for 201 HMPOs, -0.11 for 79 UCH IIs. Our result is consistent with that of He et al. (2015) although the decreasing trend is less prominent. This difference may be because their sample contains many more evolved UCH IIs than High sources in our sample.

Fuller et al. (2005) surveyed 77 submillimeter clumps associated with HMPOs in multiple molecular lines for an extensive inflow study toward high-mass star-forming regions. The blue excesses were derived to be $E=0.15$ and $E=0.19$ for the $\mathrm{HCO}^{+}(1-0)$ and $\mathrm{H}_{2} \mathrm{CO}\left(2_{12}-1_{11}\right)$ lines, respectively. When they considered only sources with distances $\leqslant 6 \mathrm{kpc}$ in order to avoid beam dilution effects due to large distances of the sources, the excesses considerably increased and became comparable to the values estimated for low-mass star-forming regions, $E \simeq 0.3$ (Evans 2003). However, we do not find such a trend in the same analysis for our sample. For instance, the blue excesses for the $\mathrm{HCO}^{+}(1-0)$ and $\mathrm{H}_{2} \mathrm{CO}\left(2_{12}-1_{11}\right)$ lines are $E=0.20$ and $E=0.13$ for the entire sample and $E=0.12$ and $E=0.16$ for the 65 and 63 sources within $6 \mathrm{kpc}$, respectively. This inconsistent result may be caused by large uncertainty in the determination of the distances to the sources. The vast majority of the sources in both our sample and Fuller et al.'s (2005) are located in the inner Galaxy, but the distance ambiguity is not resolved for most of them.

As noted in Section 3.1, Wu \& Evans (2003) found that the HCN $(3-2)$ line shows a significant blue excess $(E=0.21)$ for their sample, thus it is useful for tracing inflow motions toward UCH IIs and compact H II regions. However, we find that the transition is a much worse tracer of inflow motions toward HMPOs in our sample than the $\mathrm{HCO}^{+}(1-0)$ line. It is worthwhile to note that their sources are more massive and luminous, as well as more evolved than ours: median mass of $8.9 \times 10^{2} M_{\odot}$ and median $L_{\mathrm{IR}}$ of $1.06 \times 10^{5} L_{\odot}(\mathrm{Wu} \&$ Evans 2003) versus median $L_{\mathrm{IR}}$ of $1.11 \times 10^{4} L_{\odot}$. In fact, the critical density of the $\mathrm{HCN}(3-2)$ transition is two orders of magnitude larger than that of the $\mathrm{HCO}^{+}(1-0)$ transition (Shirley 2015). Therefore, we interpret that the $\mathrm{HCO}^{+}(1-0)$ line, which has a relatively low critical density, is better suited 
Table 5

Blue Excess Statistics for the Low and High Groups

\begin{tabular}{|c|c|c|c|c|c|c|c|c|}
\hline Transition & Group & $N_{\text {Blue }}$ & $N_{\text {Red }}$ & $N_{\text {Total }}$ & $D_{\text {Blue }}$ & $D_{\text {Red }}$ & $E$ & $P$ \\
\hline \multirow[t]{2}{*}{$\overline{\mathrm{HCO}^{+}(1-0)}$} & Low & 7 & 2 & 20 & 0.35 & 0.10 & 0.25 & 0.090 \\
\hline & High & 22 & 12 & 54 & 0.41 & 0.22 & 0.19 & 0.029 \\
\hline $\mathrm{HCO}^{+}(3-2)$ & Low & 1 & 1 & 7 & 0.14 & 0.14 & 0.00 & 0.750 \\
\hline \multirow[t]{2}{*}{$\mathrm{HCN}(3-2)$} & Low & 0 & 2 & 7 & 0.00 & 0.29 & -0.29 & 1.000 \\
\hline & High & 12 & 17 & 41 & 0.29 & 0.41 & -0.12 & 0.868 \\
\hline $\mathrm{H}_{2} \mathrm{CO}\left(2_{21}-1_{11}\right)$ & Low & 4 & 0 & 20 & 0.20 & 0.00 & 0.20 & 0.063 \\
\hline
\end{tabular}

for investigating inflow motions in our sources than the HCN (3-2) line. This seems to be consistent with the previous suggestion that the characteristic blue profile will show up only if the critical density of the molecular tracer is suitable for the optical depth of the target (Myers et al. 1996; Wu \& Evans 2003).

Although the blue profile has been widely accepted as an indicator of infall motions, as noted earlier, it is sometimes tricky to interpret the signature due to other kinematics, especially for massive star-forming regions that are much more turbulent and distant than low-mass star-forming regions. Alternatively, the redshifted absorption feature can be used to study inflow motions in massive star-forming regions because they are usually bright radio and infrared sources. For example, Wyrowski et al. $(2012,2016)$ observed 11 massive molecular clumps in the $\mathrm{NH}_{3} 3_{2+}-2_{2-}$ line at $1.81 \mathrm{THz}$ using the GREAT instrument on board SOFIA (beam size $=16^{\prime \prime}$ ). They detected redshifted $\mathrm{NH}_{3}$ absorption features with respect to the systemic velocities toward eight sources, and derived the velocity shifts to be $0.3-2.9 \mathrm{~km} \mathrm{~s}^{-1}$. Their measurements are roughly in agreement with the estimated infall velocities of this study (see Section 3.2). These two kinds of studies utilizing blue profiles and redshifted absorption features would complement each other.

\section{Conclusions and Summary}

We performed a survey of one optically thin and up to four optically thick molecular lines toward 82 HMPO candidates to understand gravitational collapse in the early stages of highmass star formation. To quantify the asymmetries of the optically thick line profiles, we derived $\delta v$ 's of the individual sources in each transition and estimated the blue excess for our sample with $\delta v= \pm 0.25$ as threshold values. The main results are summarized as follows:

1. We obtained a statistically significant blue excess in the $\mathrm{HCO}^{+}(1-0)$ line $(E=0.20)$, but nonsignificant excesses in the $\mathrm{HCO}^{+}(3-2)$ and the $\mathrm{H}_{2} \mathrm{CO}\left(2_{12}-1_{11}\right)$ lines $(E=0.09$ and $E=0.13$, respectively). The $\mathrm{HCN}(3-2)$ line shows a negative blue excess of $E=-0.15$. The $\mathrm{HCO}^{+}(1-0)$ line thus seems to be the suitable tracer of inflow motions in high-mass starforming regions, as some previous studies proposed (e.g., Fuller et al. 2005; Wu et al. 2007). On the contrary, the other lines do not appear to have a suitable opacity and critical density for the appearance of blue profile toward most sources in our sample, and may be affected by dynamics other than inflow, such as outflow, rotation, and turbulent motions.

2. We found 27 inflow candidates by adopting the criteria of Fuller et al. (2005), namely, one or more blue profiles and no red profile. All of them are newly identified inflow candidates except one (IRAS $05490+2658$ ), which had been classified by Fuller et al. (2005) as an inflow candidate. We derived inflow velocities for 20 out of the 27 candidates using the two-layer radiative transfer model of Myers et al. (1996). The estimated inflow velocities range between 0.23 and $2.00 \mathrm{~km} \mathrm{~s}^{-1}$, with a median value of $0.49 \mathrm{~km} \mathrm{~s}^{-1}$. On the other hand, there are 18 sources that have red profile(s) but no blue profile. They might be more affected by dynamics other than inflow motion in the observed optically thick lines.

3. The sources in our sample are all HMPO candidates but they are known to be divided into two different evolutionary stages: Low and High groups. The statistical results for the Low group show that blue excesses in the $\mathrm{HCO}^{+}(1-0)$ and $\mathrm{H}_{2} \mathrm{CO}\left(2_{12}-1_{11}\right)$ lines, of which the number of both groups are statistically meaningful, are slightly higher than those for High groups. We also estimated blue excesses for a subsample of sources at relatively small $(\leqslant 6 \mathrm{kpc})$ distances and obtained less significant excesses than those for the entire sample. This is not consistent with the result of Fuller et al. (2005). This discrepancy may be caused by large uncertainties in determining the distances to the sources in our sample and theirs.

We are grateful to all the staff members at KVN who helped to operate the telescope. The KVN is a facility operated by the Korea Astronomy and Space Science Institute. H.Y. and J.C.'s work is supported by the National R \& D Program through the National Research Foundation of Korea (NRF), funded by the Ministry of Education (NRF-2016R1D1A1B02015014).

\section{Appendix \\ Observed Line Profiles for all Objects}

In this appendix, we present all the detected molecular line spectra of the individual sources. Table 3 lists detailed information on the inflow statistics of these spectra. 

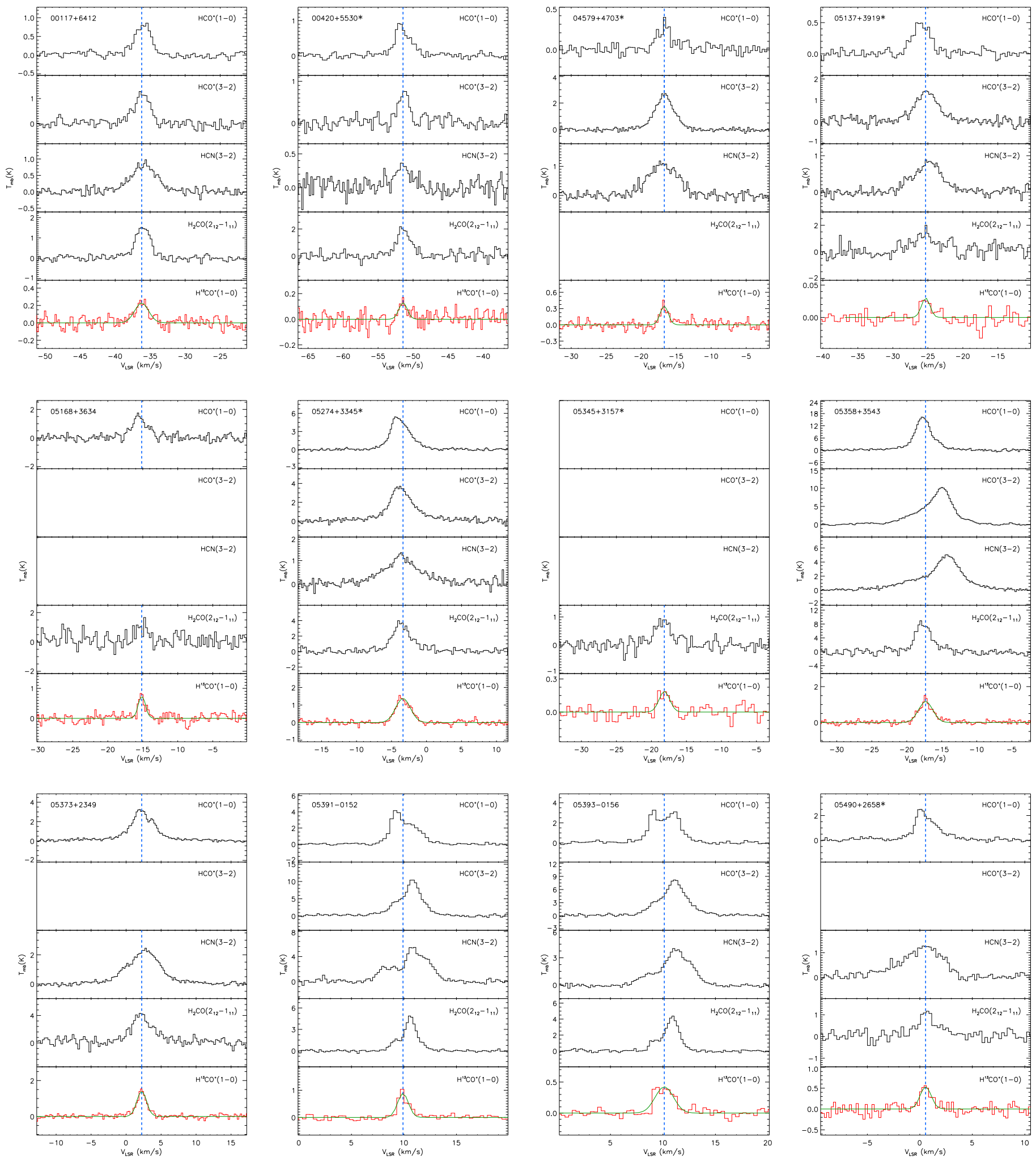

Figure 4. Detected molecular line spectra of the individual sources. For each source, the IRAS name is presented in the upper left corner in the top panel and the transition is listed in the upper right corner in each panel. The vertical blue dotted line is the central velocity of the $\mathrm{H}^{13} \mathrm{CO}^{+}(1-0)$ line determined by Gaussian fitting. The line spectrum is displayed in red with the Gaussian fitting result in green in the bottom panel. The inflow candidates are marked with asterisks on the source names. The empty panel means that the transition was not observed for a given source. 

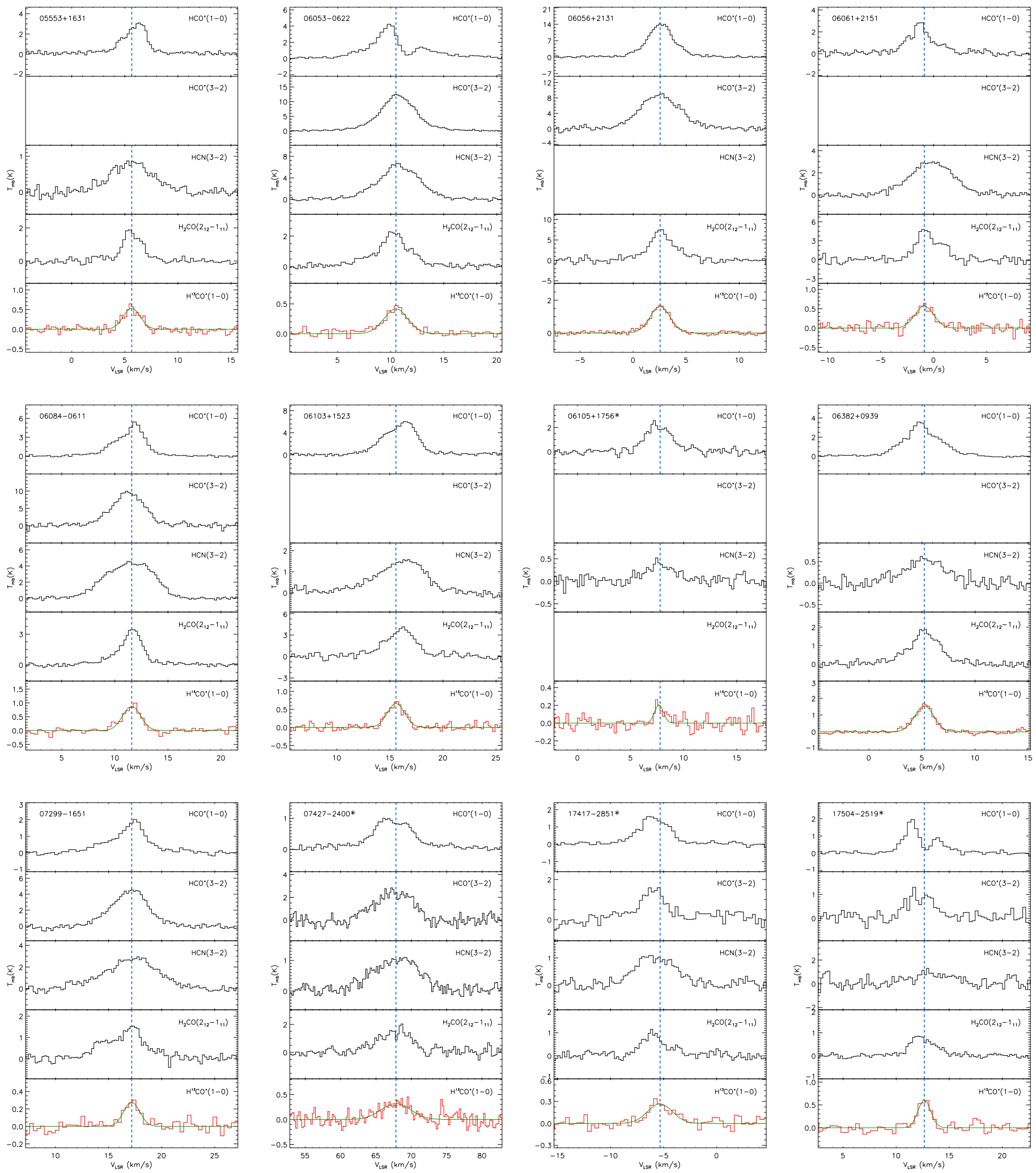

Figure 4. (Continued.) 

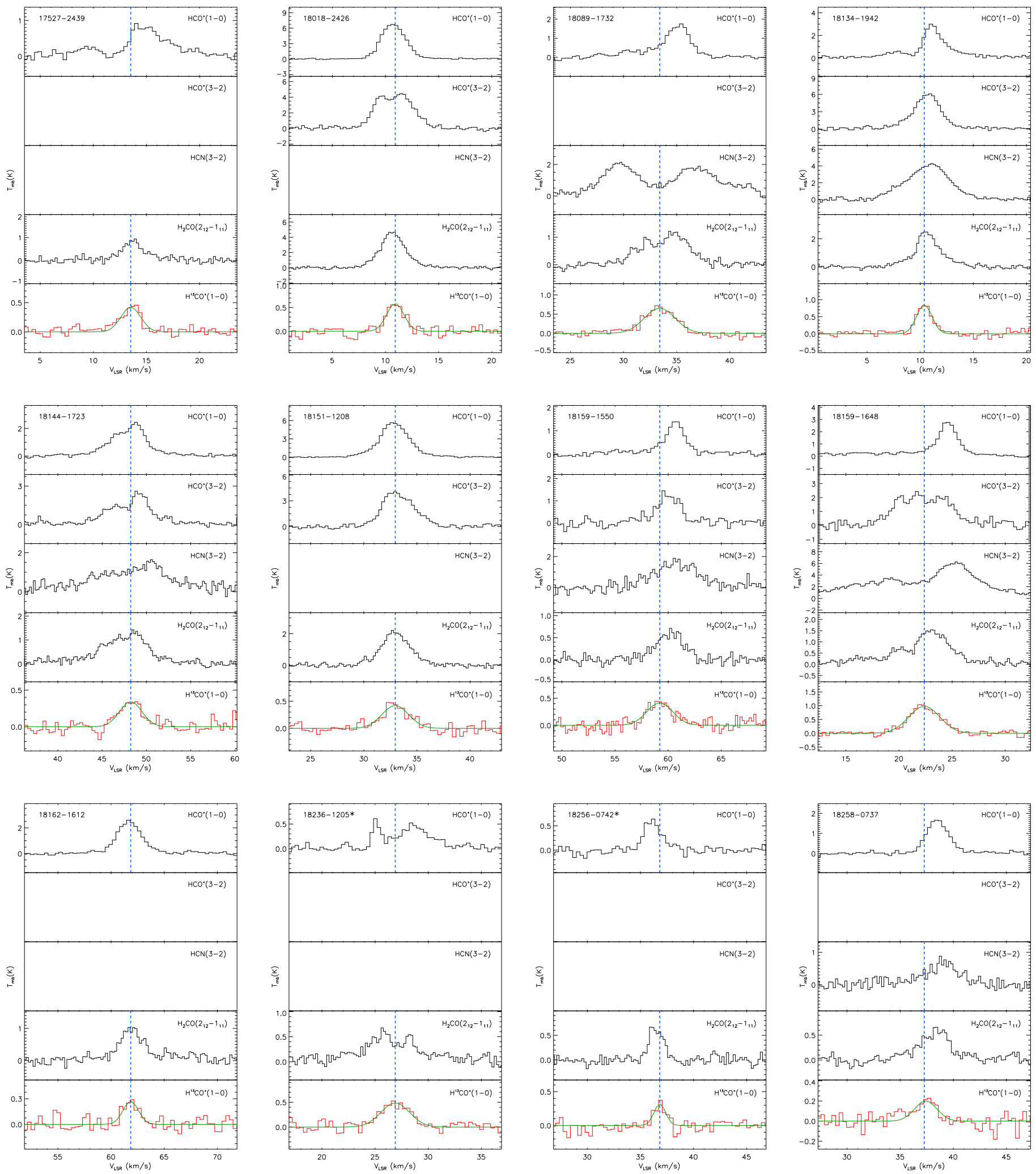

Figure 4. (Continued.) 
The Astrophysical Journal Supplement Series, 235:31 (17pp), 2018 April

Yoo et al.
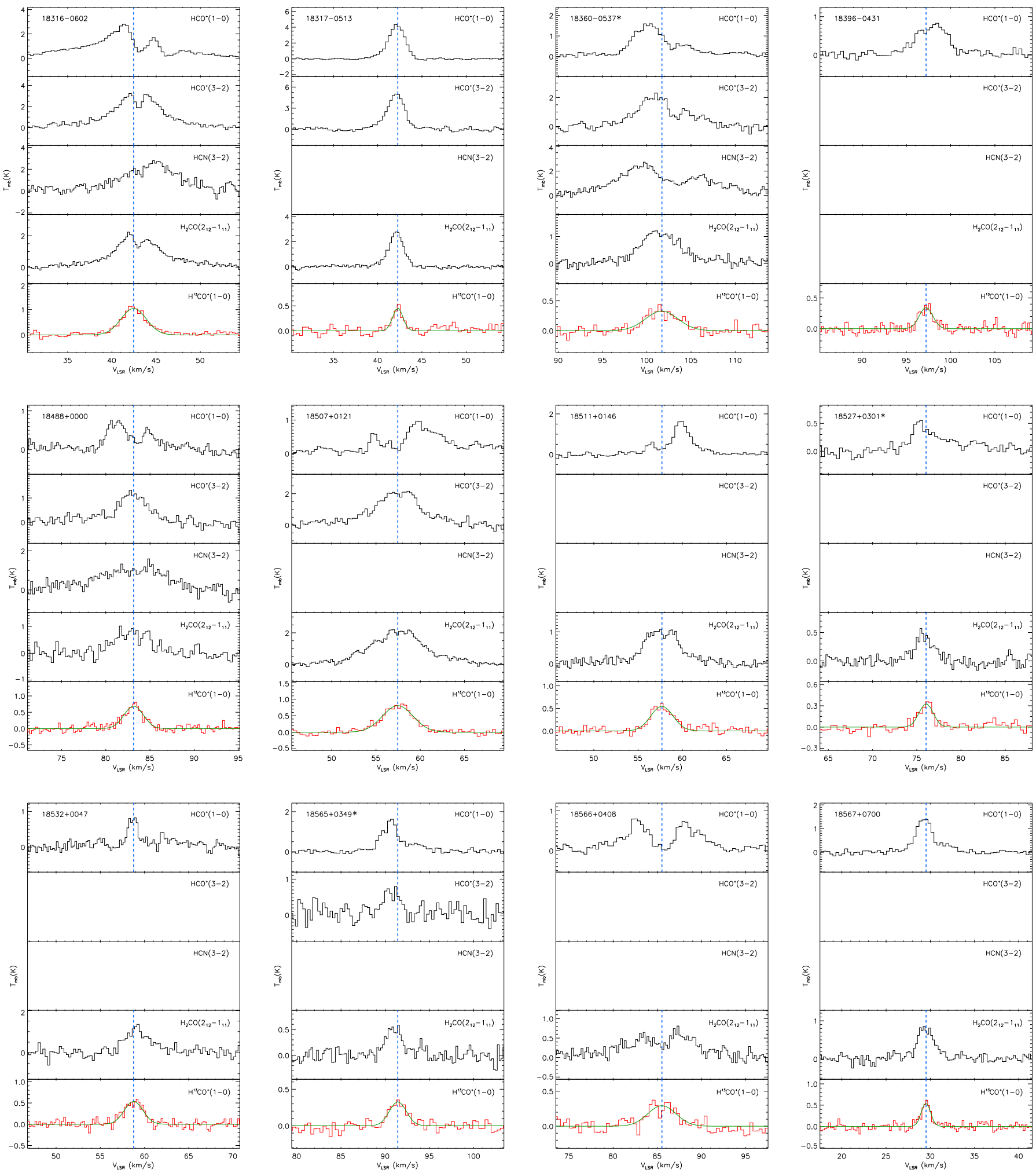

Figure 4. (Continued.) 
The Astrophysical Journal Supplement Series, 235:31 (17pp), 2018 April
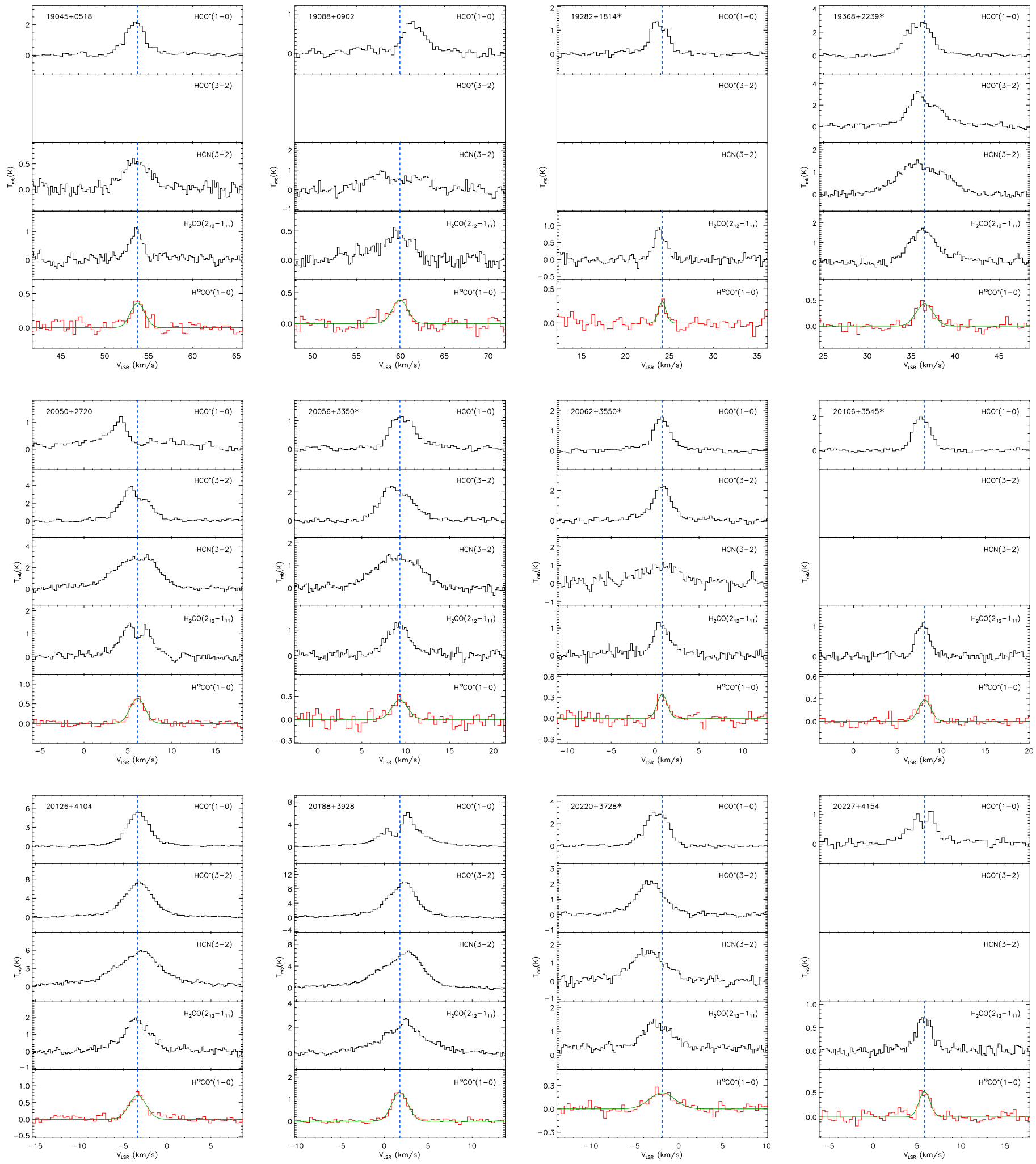

Figure 4. (Continued.) 

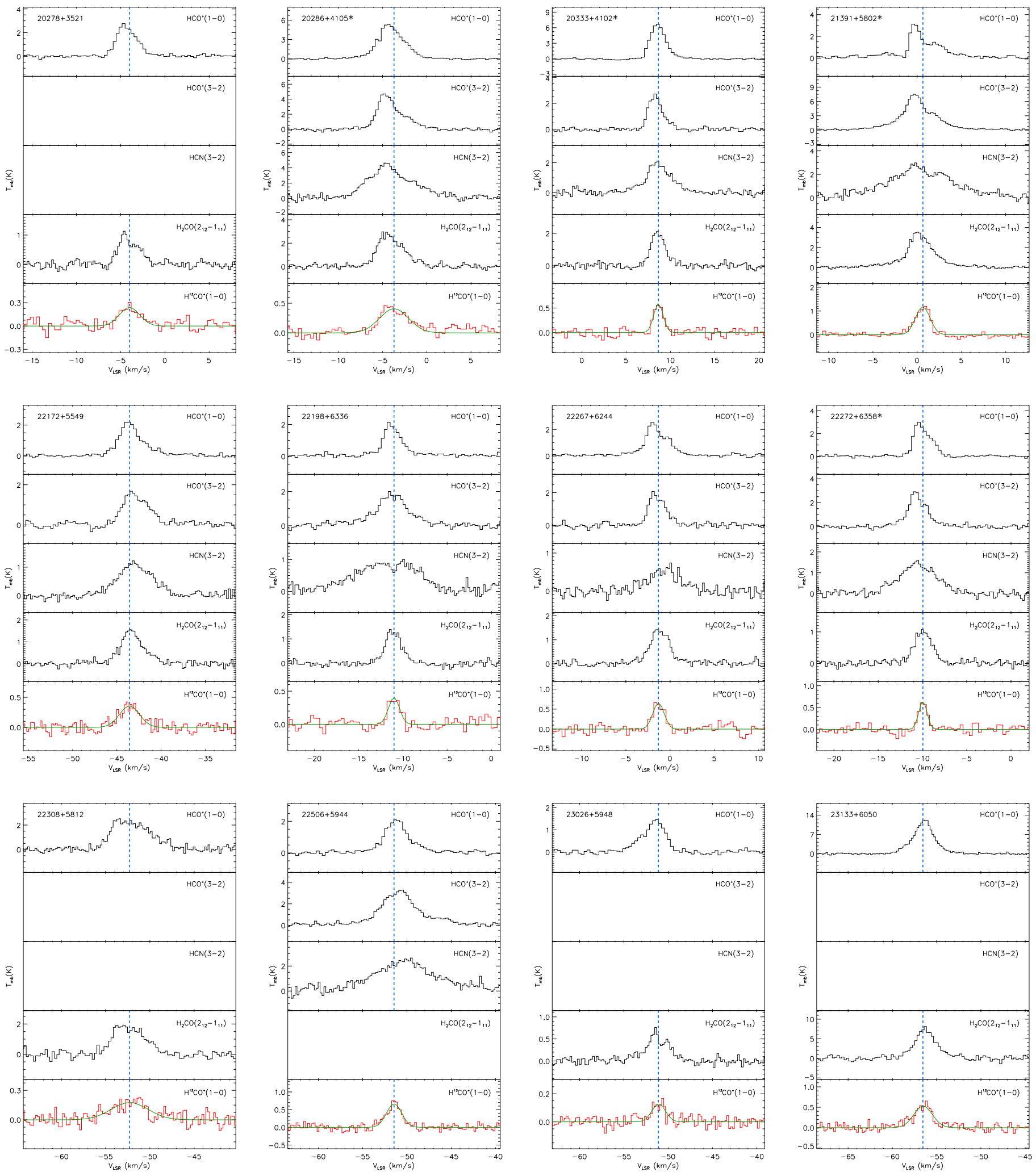

Figure 4. (Continued.) 


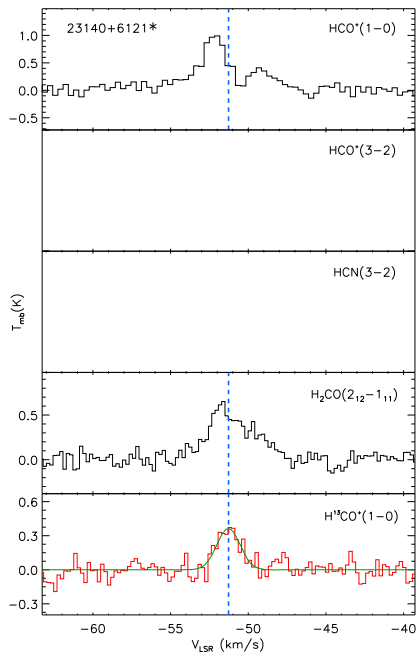

ORCID iDs

Kee-Tae Kim (10 https://orcid.org/0000-0003-2412-7092

Jungyeon Cho (i) https://orcid.org/0000-0003-1725-4376

Jingwen Wu (1) https://orcid.org/0000-0001-7808-3756

Neal J. Evans, II (1) https://orcid.org/0000-0001-5175-1777

\section{References}

Evans, N. J., II 1999, ARA\&A, 37, 311

Evans, N. J., II 2003, in SFChem 2002: Chemistry as a Diagnostic of Star Formation, ed. C. L. Curry \& M. Fich (Ottawa: NRC press), 157

Fuller, G. A., Williams, S. J., \& Sridharan, T. K. 2005, A\&A, 442, 949

Gómez, Y., Rodríguez, L. F., \& Garay, G. 2002, ApJ, 571, 901

Gregersen, E. M., Evans, N. J., II, Mardones, D., \& Myers, P. C. 2000, ApJ, 533, 440

Gregersen, E. M., Evans, N. J., II, Zhou, S., \& Choi, M. 1997, ApJ, 484, 256

He, Y.-X., Zhou, J.-J., Esimbek, J., et al. 2015, MNRAS, 450, 1926

Hunter, T. R., Churchwell, E., Watson, C., et al. 2000, AJ, 119, 2711

Jin, M., Lee, J.-E., Kim, K.-T., \& Evans, N.-J., II 2016, ApJS, 225, 21

Kim, K.-T., Byun, D.-Y., Je, D.-H., et al. 2011, JKAS, 44, 81

Klaassen, P. D., \& Wilson, C. D. 2007, ApJ, 663, 1092

Kumar, M. S. N., Bachiller, R., \& Davis, C. J. 2002, ApJ, 576, 313

Mangum, J. G. 2000, User's Manual for the NRAO 12 Meter Millimeter-Wave Telescope (Tucson, AZ: NRAO)
Mardones, D., Myers, P. C., Tafalla, M., et al. 1997, ApJ, 489, 719

Molinari, S., Brand, J., Cesaroni, R., et al. 1998, A\&A, 336, 339

Molinari, S., Brand, J., Cesaroni, R., \& Palla, F. 1996, A\&A, 308, 573

Myers, P. C., Mardones, D., Tafalla, M., et al. 1996, ApJL, 465, L133

Palla, F., Brand, J., Comoretto, G., et al. 1991, A\&A, 246, 249

Purcell, C. R., Balasubramanyam, R., Burton, M. G., et al. 2006, MNRAS, 367, 553

Qin, S.-L., Wang, J.-J., Zhao, G., et al. 2008, A\&A, 484, 361

Reiter, M., Shirley, Y. L., Wu, J., et al. 2011, ApJ, 740, 40

Richards, P. J., Little, L. T., Heaton, B. D., \& Toriseva, M. 1987, MNRAS, 228, 43

Shirley, Y. L. 2015, PASP, 127, 299

Shu, F. H. 1977, ApJ, 214, 488

Sridharan, T. K., Beuther, H., Schilke, P., et al. 2002, ApJ, 566, 931

Walsh, A. J., Bertoldi, F., Burton, M. G., \& Nikola, T. 2001, MNRAS, 326,36

Walsh, A. J., Burton, M. G., Hyland, A. R., \& Robinson, G. 1998, MNRAS, 301,640

Wood, D. O. S., \& Churchwell, E. 1989, ApJ, 340, 265

Wu, J., \& Evans, N. J., II 2003, ApJL, 592, L79

Wu, Y., Henkel, C., Xue, R., et al. 2007, ApJL, 669, L37

Wyrowski, F., Güsten, R., Menten, K. M., et al. 2012, A\&A, 542, L15

Wyrowski, F., Güsten, R., Menten, K. M., et al. 2016, A\&A, 585, A149

Wyrowski, F., Heyminck, S., Güsten, R., \& Menten, K. M. 2006, A\&A, 454, L95

Zhou, S., Evans, N. J., II, Kömpe, C., \& Walmsley, C. M. 1993, ApJ, 404, 232 